\title{
Studies of Polyelectrolyte Solutions VI. Effects of Counterion Binding by Dextran Sulfate and Dextran Phosphate in Aqueous/Organic Solvents
}

\author{
Wadou BARÉ and Eckhard NORDMEIER ${ }^{\dagger}$ \\ Department of Physical Chemistry, University of Osnabrück, 49069 Osnabrück, Germany
}

(Received March 25, 1996)

\begin{abstract}
The influence of the solvent on the degree of counterion binding of dextran sulfate and dextran phosphate is studied by activity measurements, dye-spectroscopy, and static light scattering. The solvents used are binary mixtures of water and organic solvents such as acetone, alcohol, and formamide. The mixing ratio is varied over a wide range in order to obtain different solvent dielectric constants. The results of investigations are as follows. First of all, in pure water the alkali ions are bound by dextran sulfate in the order $\mathrm{Cs}^{+}>\mathrm{K}^{+}>\mathrm{Na}^{+}>\mathrm{Li}^{+}$, i.e., the degree of counterion binding for $\mathrm{Li}^{+}$is lowest while that for $\mathrm{Cs}^{+}$is largest. The inverse ion sequence is observed for dextran phosphate. In mixed solvents the ion sequence depends on the mixture used. Secondly, there exists no universal correlation between the dielectric constant of the solvent and the degree of counterion binding. However, it is common to all aqueous/organic solvent mixtures that the degree of counterion binding decreases as the fraction of the organic compound in the solvent increases. Thirdly, condensation theory is not valid in mixed solvents, while the Poisson-Boltzmann approach may be applied. Taking into account the size of the solvated small ions we find that the type of counterion binding of a divalent counterion, such as $\mathrm{Mg}^{2+}$, depends on the kind of the univalent counterions added in excess. For water/n-propanol it seems that in the presence of $\mathrm{Li}^{+}, \mathrm{Mg}^{2+}$ is bound delocalized, while in the presence of $\mathrm{K}^{+}, \mathrm{Mg}^{2+}$ is bound by site binding. Fourthly, in water/formamide and water/dimethyl sulfoxide (DMSO) the organic solvents are adsorbed preferably by dextran sulfate. As a consequence, the dielectric constant at the polyion surface differs from that of the bulk solvent. Nevertheless, if these changes are taken into account, the predictions of condensation theory remain contradictory to the results of measurements.

KEY WORDS Dextran Sulfate / Dextran Phosphate / Counterion Binding / Mixed Solvents / Activity Coefficients / Dielectric Constants / Dye Spectroscopy / Static Light Scattering /
\end{abstract}

There has been great interest in studying the interactions between polyion and simple electrolytes, as this information provides a key to the understanding of biological processes since many biopolymers are polyelectrolytes. A well established result has been that an extra amount of counterions will bind on the polyion of almost all bulk counterions. For instance, in previous reports, ${ }^{1-3}$ we have shown that the polyion charge density and the kind of charged groups play an important role for the degree of counterion binding, but it is also expected that the solvent, in which the polyelectrolyte chains are dissolved, have some influence. Studies in water and aqueous/organic solvent mixtures are therefore very important. The reasons are:

1. A certain property of the solvent such as a define value of the dielectric constant, $\varepsilon_{\mathrm{r}}$, or a particular value of the refractive index, $n$, can be more precisely adjusted in mixed than in single solvents. This is simply achieved by choosing an appropriate solvent composition, i.e., taking the mass fraction, $w_{\mathrm{o}}$, of the organic component appropriately.

2. In a mixed solvent the molar ratio of the two solvent components at the polyion surface differs from the molar ratio of the polyion-free solvent. This is due to the fact that the polyion generally has a higher affinity to one of the solvent components. The phenomenon is called preferential or selective solvent adsorption. Its investigation leads to a deeper comprehension of the respective affinity of each solvent with regard to the polyion and its influence on the polyion molecular dimensions. In most cases, the radius of gyration, $\left\langle S^{2}\right\rangle_{Z}^{1 / 2}$, of the poly-

\footnotetext{
${ }^{\dagger}$ To whom correspondence should be addressed.
}

ion increases with increasing mass fraction, $w_{0}$, of the organic solvent component and above a critical solvent composition, $w_{\mathrm{o}, \mathrm{c}}$, the polyion contracts. ${ }^{4,5}$

3 . In a mixed solvent the hydrophobicity around the ionizable groups of the polyion chain may influence the selectivity of counterion binding of polyelectrolytes.

Recently, ${ }^{2}$ we have investigated the effect of solvent on the counterion binding of poly(styrene sulfate) (PSS). It was found that the degree of counterion binding increases with decreasing dielectric constant of the solvent, a result that is in agreement with Manning's condensation theory. ${ }^{7}$ In this paper we study the physicochemical properties of dextran sulfate (DS) and dextran phosphate (DP). They are branched polyelectrolytes while PSS is a linear polyelectrolyte. That is, an important question is: Does branching change the correlation between counterion binding and solvent properties or does it not? The solvent mixtures used for DS and DP are water/methanol, water/ethanol, water $/ n$-propanol, water/acetone, and water/dimethyle sulfoxide. Static light scattering measurements yield the coefficient, $\alpha_{a}$, of selective solvent adsorption. A positive value of $\alpha_{a}$ indicates a preferential adsorption of water. The organic solvent component is preferentially adsorbed if $\alpha_{\mathrm{a}}$ is negative. Activity coefficients are determined for the alkali ions. They give information about selectivity in counterion binding. Finally, dye spectroscopic measurements are applied to determine the degree of counterion binding, $\theta_{2}$, of divalent metal ions in solutions containing univalent ions in excess, i.e., in solutions where both the ratio of polyion to univalent ion concentration and the ratio of divalent ions to univalent ions are smaller than unity. Such experiments are interesting because they 
give information about the competition for counterion binding between counterions of different valence. The goals of this study are threefold:

1. We examine the phenomena of counterion binding of DS in mixed solvents and compare them with those of DP. As far as we know, such investigations have never been performed before.

2. We prove whether counterion condensation theory is able to describe the results of measurements.

3. We interpret the results in the frame of the Poisson-Boltzmann approach. This opens new insights which are surprising in many aspects.

\section{THEORY}

\section{Activity Coefficients}

There exist a number of theoretical calculations for the activity coefficients of small ions in salt containing polyelectrolyte solutions. The additivity rule originally proposed by Mock and Marshall ${ }^{6}$ can be formulated, for $1: 1$ added electrolytes, as:

$$
\frac{\gamma_{ \pm}}{\gamma_{ \pm}^{0}}=\left[\left(\frac{\gamma_{c}}{\gamma_{ \pm}^{0}}+X^{-1}\right)\left(1+X^{-1}\right)^{-1}\right]^{-1 / 2}
$$

where $X$ is $c_{\mathrm{p}} / c_{\mathrm{s}}$, the ratio of the equivalent polyelectrolyte concentration, $c_{\mathrm{p}}$, to that of the simple salt $c_{\mathrm{s}} \cdot \gamma_{ \pm}$is the activity coefficient of the added salt in the polyelectrolyte salt mixture, $\gamma_{ \pm}^{0}$ is the activity coefficient in the pure electrolyte at the same concentration $c_{\mathrm{s}}$ as in the mixture, and $\gamma_{c}$ is the counterion activity coefficient in the pure polyelectrolyte solution at $c_{\mathrm{p}}$. Equation 1 possesses a purely empirical character.

The direct determination of $\gamma_{c}$ can be questioned, because it suffers of reproducibility. Therefore, many workers use $\gamma_{c}$ as an adjustable parameter.

Manning's ${ }^{7}$ expressions for the counterion, coion, and mean activity coefficients of an added 1:1 electrolyte, depend on the value of the charge density parameter, $\xi$. For $\xi \leq Z_{\mathrm{c}}{ }^{-1}$, where $Z_{\mathrm{c}}$ is the valence of the counterion, it holds:

$$
\gamma_{\mathrm{c}}=\gamma_{\mathrm{co}}=\gamma_{ \pm}=\exp (-0.5 \xi X /(X+2))
$$

with $\gamma_{ \pm} \equiv\left(\gamma_{\mathrm{c}} \gamma_{\mathrm{co}}\right)^{0.5}$. The index c stands for counterion and co for coion. When $\xi \geq Z_{\mathrm{c}}{ }^{-1}$ counterions condense (bind to) on the polyion until $\xi=\left|Z_{\mathrm{c}}\right|^{-1}$, and the remaining uncondensed counterions interact with the polyion by Debye-Hückel interactions. In this case the expressions for $\gamma_{c}$ and $\gamma_{c o}$ are different. We then have:

$$
\begin{aligned}
& \gamma_{\mathrm{c}}=\frac{\xi^{-1} X+1}{X+1} \exp \left(\frac{-\frac{1}{2} \xi^{-1} X}{\xi^{-1} X+2}\right) \\
& \gamma_{\mathrm{co}}=\exp \left(\frac{-\frac{1}{2} \xi^{-1} X}{\xi^{-1} X+2}\right) \\
& \gamma_{ \pm}^{2}=\frac{\xi^{-1} X+1}{X+1} \exp \left(\frac{-\xi^{-1} X}{\xi^{-1} X+2}\right)
\end{aligned}
$$

with

$$
\xi=\frac{e^{2}}{4 \pi \varepsilon_{0} \varepsilon_{\mathrm{r}} k_{\mathrm{B}} T b}
$$

Experimental investigations ${ }^{8,9}$ show that the DebyeHückel approximation is not always sufficiently accurate to describe the polyion small ion interactions. In many cases, there is a large discrepancy in coion and counterion activities for polyions where $\xi$ is lower than $\left|Z_{\mathrm{c}}\right|^{-1}$. To describe this effect Iwasa et al. ${ }^{10,11}$ derived new laws for the activity coefficients, using the cluster theory. The expressions for an added 1:1 electrolyte of valence 1 are:

For $\xi \leq 1$

$$
\begin{aligned}
& \gamma_{\mathrm{c}}=\exp \left[\left(-0.5+0.39 \xi\left(\frac{X}{X+2}-1\right)\right) \frac{\xi X}{X+2}\right] \\
& \gamma_{\mathrm{co}}=\exp \left[\left(-0.5+0.39 \xi\left(\frac{X}{X+2}+1\right)\right) \frac{\xi X}{X+2}\right] \\
& \gamma_{ \pm}=\exp \left[\left(-0.5+0.39 \frac{\xi X}{X+2}\right) \frac{\xi X}{X+2}\right]
\end{aligned}
$$

For $\xi>1$

$$
\begin{aligned}
\gamma_{\mathrm{c}}= & \frac{\xi^{-1} X+1}{X+1} \\
& \times \exp \left\{\frac{\xi^{-1} X}{\xi^{-1} X+2}\left[-0.5+0.39\left(\frac{\xi^{-1} X}{\xi^{-1} X+2}-1\right)\right]\right\} \\
\gamma_{\mathrm{co}}= & \exp \left\{\frac{\xi^{-1} X}{\xi^{-1} X+2}\left[-0.5+0.39\left(\frac{\xi^{-1} X}{\xi^{-1} X+2}+1\right)\right]\right\} \\
\gamma_{ \pm}= & \left.\frac{\xi^{-1} X+1}{X+1}\right)^{0.5} \\
& \times \exp \left\{\frac{\xi^{-1} X}{\xi^{-1} X+2}\left[-0.5+0.39\left(\frac{\xi^{-1} X}{\xi^{-1} X+2}-1\right)\right]\right\}
\end{aligned}
$$

For salt-free polyelectrolyte solutions $X$ converges to infinite. Iwasa's expressions are then identical with those obtained by Manning.

\section{Degrees of Counterion Binding}

In the following we study polyion systems containing two kinds of counterions simultaneously, i.e., univalent 1 and divalent counterions 2 . The corresponding degrees of counterion binding, $\theta_{1}$ and $\theta_{2}$, can be calculated from the two variable theory of Manning. ${ }^{12}$ It holds,

$$
\begin{aligned}
1+\ln \left(\frac{\theta_{1}}{V_{\mathrm{c}} c_{\mathrm{s}, 1}}\right) & =-2 \xi\left(1-\theta_{1}-2 \theta_{2}\right) \ln \left(1-e^{-\kappa b}\right) \\
\ln \left(\theta_{2} / c_{\mathrm{s}, 2}\right) & =\ln \left(\frac{V_{\mathrm{c}}}{2.72}\right)+2 \ln \left(\frac{2.72 \theta_{1}}{V_{\mathrm{c}} c_{\mathrm{s}, 1}}\right)
\end{aligned}
$$

where $c_{\mathrm{s}, 1}$ and $c_{\mathrm{s}, 2}$ are the molar concentrations of counterions 1 and 2, respectively. $\kappa$ is the Debye-Hückel parameter and $V_{\mathrm{c}}$ is the condensation volume, i.e., the volume around the polyion in which the counterions are 
territorially bound. At the limit $\theta_{2} \rightarrow 0$ we have

$$
V_{\mathrm{c}}=2.72\left(1-\xi^{-1}\right)\left(\frac{(\kappa b)^{2}}{c_{\mathrm{s}, 1}}\right)
$$

Equations 13 and 14 can be solved as follows: We resolve eq. 13 according to $\theta_{2}$ and insert the relation obtained for $\theta_{2}$ into eq 14 . Then eq 14 is solved by iteration for $\theta_{1}$, and finally $\theta_{2}$ is obtained by inserting $\theta_{1}$ into eq 13 .

It should be noted that eq 13 and 14 are valid only when the total ionic strength sufficiently exceeds the polyion concentration $c_{\mathrm{p}}$, so that the influence of the polyion on the small ion activities through long range interactions can be neglected. That is, the condition $c_{\mathrm{p}} / c_{\mathrm{co}} \ll 1$, where $c_{\mathrm{co}}$ is the total coion concentration $\left(c_{\mathrm{co}}=c_{\mathrm{s}, 1}+2 c_{\mathrm{s}, 2}-c_{\mathrm{p}}\right)$, must be fulfilled.

\section{EXPERIMENTAL}

\section{Materials}

Sodium dextran sulfate (NaDS), average molar mass $5 \times 10^{5} \mathrm{~g} \mathrm{~mol}^{-1}$, was purchased from Fluka. The degree of substitution by sulfate groups, determined by elementary analysis, was 2 per glucose ring. This gives an average charge density parameter, $\xi$, of 2.8. Dextran phosphate was prepared from the purified parent dextran (Sigma, $M_{w}=2.4 \cdot 10^{5} \mathrm{~g} \mathrm{~mol}^{-1}$ ) according to the method of Whistler and Towle. ${ }^{13}$ The degree of substitution by phosphate groups, determined by elementary analysis and potentiometric titration, was 0.5 per glucose ring. Thus, the average value $\xi$ of DP is 1.6.

Aqueous solutions of these materials were passed through a column of mixed bed ion-exchange (Lewatit S100, Bayer AG) and the acid form of the polymers was purified by ultrafiltration (Ultrasart Cell 50, Sartorius). Afterwards the solutions were completely neutralised with different alkalihydroxides (Merck) by potentiometric titration. This yields the DS and DP salts, respectively.

The inorganic salts such as $\mathrm{LiCl}, \mathrm{NaCl}, \mathrm{KCl}, \mathrm{CsCl}$, $\mathrm{RbCl}, \mathrm{MgCl}_{2}, \mathrm{CaCl}_{2}$, and $\mathrm{Cd}\left(\mathrm{NO}_{3}\right)_{2}$ were from Merck (reagent grade). They were used without further purification. $\mathrm{Mg}^{2+}$ activities were determined by the two wavelength dye spectroscopic method described by Kwak et $a l .{ }^{14}$ The buffer, tris(hydroxymethylamino)methane, was adjusted with $\mathrm{HCl}$ to $\mathrm{pH}=7.6$; the dye used was Eriochrome Black T (EBT). Experimental procedures, instruments, and calculations were the same as described in ref 14 . Needed $\mathrm{MgCl}_{2}$ activity coefficients were interpolated from literature values. ${ }^{15}$ All solutions were made up by weight using deionised water or mixtures of deionised water and an organic solvent of reagent grade, such as acetone, formamide, methanol, ethanol, or $n$ propanol (Merck and Aldrich).

\section{Activities Measurements}

The activities of the cations $\mathrm{Na}^{+}, \mathrm{K}^{+}, \mathrm{Ca}^{2+}$, and $\mathrm{Cd}^{2+}$ were determined with ion-sensitive electrodes from Metrohm. In detail we used the glass membrane electrode 6.0501.100 for $\mathrm{Na}^{+}$, the crystal membrane electrode 6.0502.110 for $\mathrm{Cd}^{2+}$, and the polymer membrane electrodes, 6.0504.110 and 6.0504.100, for $\mathrm{K}^{+}$and $\mathrm{Ca}^{2+}$, respectively. The reference electrode was a $\mathrm{Ag} / \mathrm{AgCl}$ electrode (6.0726.xxx). All e.m.f. measurements were made with an Orion $801 \mathrm{~A}$ research $\mathrm{pH}$ meter utilising a $0.2 \mathrm{mV}$ scale. Calibration of the apparatus and the electrodes were performed with solutions of $\mathrm{CaCl}_{2}$, $\mathrm{Cd}\left(\mathrm{NO}_{3}\right)_{2}, \mathrm{KCl}$, and $\mathrm{NaCl}$. Electrode slopes were Nernstian and were never found to differ by more than $1 \mathrm{mV} /$ decade (usually less) between two calibrations.

The degree of counterion binding, $\theta$, of the cations on the polyions was calculated as:

$$
\theta=\frac{a_{\mathrm{c}}^{0}-a_{\mathrm{c}}^{p}}{a_{\mathrm{c}}^{0}}
$$

Here, $a_{\mathrm{c}}^{\mathrm{p}}$ and $a_{\mathrm{c}}^{0}$ are the activities of the cations in the polyion solution at salt concentration $c_{\mathrm{s}}$ and in a salt solution at the same concentration but without polyions.

\section{Static Light Scattering}

Static light scattering studies were performed with an ALV-3000 spectrometer, working with vertically polarized light of wavelength $\lambda_{0}=633 \mathrm{~nm}$ and a photometer FICA 50 from SOFICA using unpolarized light of wavelength $546 \mathrm{~nm}$. Absolute calibration was made with toluene. The scattering angles ranged from $30^{\circ}$ to $140^{\circ}$, and the temperature was controlled to be constant within $\pm 0.05^{\circ} \mathrm{C}$. The solutions were centrifugated for $2 \mathrm{~h}$ at $10000 \mathrm{rpm}$. Final concentrations were determined by potentiometric titrations.

Data analysis was performed as follows. According to Ooi, ${ }^{16}$ the relative intensity of the scattered light from polymers in mixed solvents is given by

$$
\frac{K c}{R(q, c)}=\frac{1}{M_{\mathrm{app}}}\left(1+\frac{1}{3}\left\langle S^{2}\right\rangle_{\mathrm{z}} q^{2}\right)+2 \frac{M_{w}}{M_{\mathrm{app}}} A_{2} c+\cdots
$$

with

$$
\begin{gathered}
K=k \pi^{2} n_{0}^{2} \frac{\left(\left.\frac{\mathrm{d} n}{\mathrm{~d} c}\right|_{\phi, \mathrm{c}_{\mathrm{s}}}\right)^{2}}{N_{\mathrm{A}} \lambda_{0}^{4}} \\
q=\frac{4 \pi n_{0}}{\lambda_{0}} \sin \left(\frac{\vartheta}{2}\right)
\end{gathered}
$$

where $k$ is 2 for unpolarized and 4 for vertically polarized light. $c$ is the polyelectrolyte salt concentration in $\mathrm{g} \mathrm{cm}^{-3}$, $R(q, c)$ the Rayleigh ratio at wave vector $q$ and concentration $c, n_{0}$ the refractive index of the solvent, $\mathrm{d} n /\left.\mathrm{d} c\right|_{\phi, c_{\mathrm{s}}}$ the refractive index increment of the solution at constant volume fraction, $\phi$, of the organic solvent component and at constant salt concentration $c_{\mathrm{s}}, N_{\mathrm{A}}$ the Avogadro number, $\lambda_{0}$ the wavelength in vacuum, $\vartheta$ the scattering angle, $\left\langle S^{2}\right\rangle_{Z}$ the Z-average square radius of gyration, and $A_{2}$ the second virial coefficient. $M_{\text {app }}$ and $M_{w}$ are the apparent and the real molar mass of the polyelectrolyte molecule. Its holds:

$$
M_{\mathrm{app}}=M_{w}\left[1+\alpha_{a} \frac{\left(\left.\frac{\mathrm{d} n_{0}}{\mathrm{~d} \phi}\right|_{c_{\mathrm{s}}}\right)}{\left(\left.\frac{\mathrm{d} n}{\mathrm{dc}}\right|_{\phi, c_{\mathrm{s}}}\right)}\right]^{2}
$$


In eq $20 \mathrm{~d} n_{0} /\left.\mathrm{d} \phi\right|_{c_{\mathrm{s}}}$ is the refractive index increment of the solvent at constant salt concentration $c_{\mathrm{s}}$, and $\alpha_{\mathrm{a}}$ is the selective adsorption coefficient. A negative value of $\alpha_{a}$ indicates a preferential adsorption of the organic solvent component by the polyion surface. Water is adsorbed preferably if $\alpha_{\mathrm{a}}$ is positive. $\mathrm{d} n_{0} /\left.\mathrm{d} \phi\right|_{c_{\mathrm{s}}}$ and $\mathrm{d} n_{0} /\left.\mathrm{d} \phi\right|_{\phi, c_{\mathrm{s}}}$ were obtained by refractometry using a differential refractometer of the Brice Phoenix type operating at 633 or $546 \mathrm{~nm} . M_{w}$ was determined by static light scattering in a 0.5 molar aqueous solution of $\mathrm{NaCl}$. This solution was dialysed against the pure solvent (water + salt). This makes sure that solution and solvent possess the same chemical potential: otherweise $M_{w}$ would differ from the true molar mass (see for instance Casassa and Eisenberg ${ }^{17}$ ). The data analysis was as follows. Equation 17 contains three unknown quantities: $M_{\mathrm{app}},\left\langle S^{2}\right\rangle_{Z}$, and $A_{2}$. They were determined by multiple regression. After that $a_{\mathrm{a}}$ was determined from eq 20 .

\section{RESULTS AND DISCUSSION}

\section{Activity Coefficients}

Figure 1 shows plots of the activity coefficient ratio, $\gamma_{ \pm}^{c}=\gamma_{ \pm} / \gamma_{ \pm}^{0}$, versus the concentration ratio, $X=c_{\mathrm{p}} / c_{\mathrm{s}}$, measured at $25^{\circ} \mathrm{C}$ in aqueous solutions of different salt/DS mixtures. The added salt concentration, $c_{\mathrm{s}}$, is varied so that $X$ ranges from 0 to 12 at each polyion concentration $c_{\mathrm{p}}$. Values of the activity coefficients, $\gamma^{0} \pm$, of the added salt in the absence of DS were obtained from the extended Debye-Hückel equation. ${ }^{18}$ In Figure 1 are also shown the theoretical curves calculated from the Manning and Iwasa laws. The curves designated by $\cdots$ (Manning) and (-.- ) (Iwasa) describe $\gamma_{ \pm} / \gamma_{ \pm}^{0}$, while the curves designated by _- (Manning) and -(Iwasa) present $\gamma_{\mathrm{c}} / \gamma_{\mathrm{c}}^{0}$. For each of the polyion/salt systems studied, the measured activity coefficient ratios follow qualitatively the theoretical predictions. That is, $\gamma_{ \pm} / \gamma_{ \pm}^{0}$ decreases with increasing $X$ from $\gamma_{ \pm} / \gamma_{ \pm}^{0}=1$ at $X=0$ to the salt free value at $X=\infty$. Three systems are investigated in detail. They are $\mathrm{HDS} / \mathrm{KCl}$ with $c_{\mathrm{p}}=$

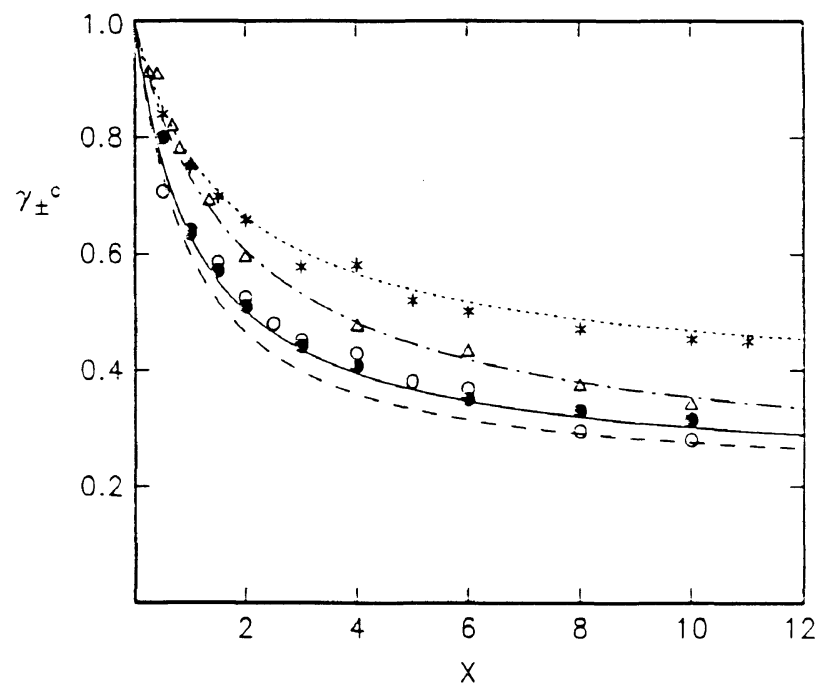

Figure 1. Activity coefficients of univalent counterions for the systems $\mathrm{KCl} / \mathrm{HDS}\left(\bigcirc\right.$ for $c_{\mathrm{p}}=2 \times 10^{-3} \mathrm{~mol} \mathrm{dm}^{-3} ; \bigcirc$ for $c_{\mathrm{p}}=4 \times 10^{-3}$ mol dm ${ }^{-3}$ ), $\mathrm{NaCl} / \mathrm{HDS}(\triangle$ ), and $\mathrm{NaCl} / \mathrm{NaDS}$ (dialysed in tris-buffer, *). The theoretical curves for $\gamma_{+} / \gamma_{+}{ }^{0}$ and $\gamma_{+} / \gamma_{+}{ }^{0}$ are from Manning $(\cdots \cdots$ and - , and, from Iwasa ( $-\cdot-$ and --$)$, respectively.

Polym. J., Vol. 28, No. 8, 1996
$2 \times 10^{-3} \mathrm{~mol} \mathrm{dm}^{-3}(\bigcirc)$ and $c_{\mathrm{p}}=4 \times 10^{-3} \mathrm{~mol} \mathrm{dm}^{-3}(\bigcirc)$, $\mathrm{HDS} / \mathrm{NaCl}$ with $c_{\mathrm{p}}=2 \times 10^{-3} \mathrm{moldm}^{-3}(\triangle)$, and $\mathrm{NaDS} / \mathrm{NaCl}$ with $c_{\mathrm{p}}=2 \times 10^{-3} \mathrm{moldm}^{-3}(*)$. The plotted data of $\mathrm{HDS} / \mathrm{KCl}$ demonstrate that, for the concentration range studied, $\gamma_{\mathrm{KCl}} / \gamma_{\mathrm{KCl}}^{0}$ is independent of the polyion concentration, $c_{\mathrm{p}}$, at any given value of $X$. This is in accord with both theories, which predict that $\gamma_{ \pm} / \gamma_{ \pm}^{0}$ depends only on the ratio $X=c_{\mathrm{p}} / c_{\mathrm{s}}$ and not on the concentration of either component (polyion or salt). On the other hand, the experimental curves show a clear dependence on the type of salt, a dependence which is neither predicted by Manning's nor by Iwasa's limiting laws. For a given $X, \gamma_{ \pm} / \gamma_{ \pm}^{0}$ is seen to go up as we exchange $\mathrm{KCl}$ by $\mathrm{NaCl}$. This indicates the ion squence $\mathrm{Na}^{+}<\mathrm{K}^{+}$, i.e., $\mathrm{K}^{+}$may be bound stronger by $\mathrm{DS}$ than $\mathrm{Na}^{+}$does. Further investigations show that for DS the ion sequence $\mathrm{Li}^{+}<\mathrm{Na}^{+}<\mathrm{K}^{+}<\mathrm{Cs}^{+}$holds, while for DP the opposite sequence is obtained. Other reports ${ }^{19,20}$ on activity measurements on DS and polyphosphate (PP) are interpreted in the same manner, but there are also reports ${ }^{21}$ where the opposite sequence is observed. In addition, there are reports ${ }^{8}$ where $\gamma_{+} / \gamma_{+}^{0}$ depends on the polyion concentration $c_{\mathrm{p}}$ and where the ion sequence vanishes when $c_{\mathrm{p}}$ is very low. The differences in the activity coefficients of the pure alkalhalides at higher concentrations can be described quite well in accordance with the differences of the Stokes radii of hydration of the alkali ions (see Robinson and Stokes ${ }^{15}$ ). They vanish at low values of $c_{\mathrm{s}}$.

In a solution where alkali dextran sulfate is in excess $(X \gg 1)$, the mean activity coefficient of the alkalihalide is largely determined by the counterion activity coefficient, while the contribution of the coion can reasonably be assumed rather small. That is, in comparison with the pure alkalihalides, one could conclude that there is no specific interaction between dextran sulfate and alkali counterions, the ion sequence being due to a difference in hydration number similar to what is observed in pure alkali solutions. However, we don't believe that this explanation is true. The ion sequence of dextran phosphate is inverse to that of dextran sulfate and there is no plausible explanation why there are specific interactions between DP and alkali counterions while there are no interactions with DS. Thus, we conclude that there are interactions. They depend on the polyion type and on the specific type of polyion salt. Figure 1 shows that the activity ratios of the system $\mathrm{NaDS} / \mathrm{NaCl}$ are significantly larger than those of the system $\mathrm{HDS} / \mathrm{NaCl}$. Since the effective charge of a HDS molecule is smaller than that of a NaDS molecule, this indicates that the alkali ion/polyion interactions are stronger the larger the polyion charge is.

In Figure 1, the observed activity coefficient ratios of the system $\mathrm{NaDS} / \mathrm{NaCl}$ are in reasonable quantitative agreement with the Manning predictions $(\cdots)$ and above the Iwasa predictions (-.-). However, to test the Manning and the Iwasa laws more significantly, experiments should be performed by using polyion systems whose charge density, $\xi$, can be varied over a wide range, without altering the chemical structure or the molar mass of the polyions. The parameter $\xi$ is defined as $\xi=$ $e^{2} /\left(4 \pi \varepsilon_{0} \varepsilon_{\mathrm{r}} k_{\mathrm{B}} T b\right)$. To vary $\xi$ one can vary the average axial spacing, $b$, between two neighbouring charged 
groups on the polyion. This was done by Kowblansky and Zema, ${ }^{9}$ who studied aqueous solutions containing fully neutralized poly(acrylamide- $c o$-acryl acid) copolymers, whose $\xi$ values ranged from 0.02 to 2.85 . The other possibility, studied here, is to vary the dielectric constant, $\varepsilon_{\mathrm{r}}$, of the solvent. This can be simply achieved by using aqueous/organic solvent mixtures, where $\varepsilon_{\mathrm{r}}$ is varied by changing the mass fraction, $w_{\mathrm{o}}$, of the organic component

Table I. Dielectric constants, $\varepsilon_{\mathrm{r}}$, of some selected solvent mixtures and the corresponding charge densities,

$\xi$, of dextran sulfate, calculated from eq 6 for $T=25^{\circ} \mathrm{C}$

\begin{tabular}{|c|c|c|c|c|c|c|c|c|c|c|}
\hline \multirow{2}{*}{$w_{0} / \%$} & \multicolumn{2}{|c|}{ Acetone } & \multicolumn{2}{|c|}{ Formamide } & \multicolumn{2}{|c|}{$\mathrm{MeOH}$} & \multicolumn{2}{|c|}{$\mathrm{EtOH}$} & \multicolumn{2}{|c|}{$n$-PrOH } \\
\hline & $\varepsilon_{\mathrm{r}}^{\mathrm{a}}$ & $\xi$ & $\varepsilon_{\mathrm{r}}^{\mathrm{b}}$ & $\xi$ & $\varepsilon_{\mathrm{r}}^{\mathrm{b}}$ & $\xi$ & $\varepsilon_{\mathrm{r}}^{\mathrm{b}}$ & $\xi$ & $\varepsilon_{\mathrm{r}}^{\mathrm{a}}$ & $\xi$ \\
\hline 10 & 73.0 & 3.01 & 85.4 & 2.57 & 74.1 & 2.97 & 72.8 & 3.02 & 71.8 & 3.06 \\
\hline 20 & 67.0 & 3.28 & 90.4 & 2.43 & 69.2 & 3.18 & 67.0 & 3.28 & 64.9 & 3.39 \\
\hline 30 & 61.0 & 3.60 & 94.5 & 2.33 & 64.3 & 3.42 & 61.1 & 3.60 & 57.7 & 3.81 \\
\hline 40 & 54.6 & 4.03 & 98.0 & 2.24 & 59.6 & 3.69 & 55.0 & 4.00 & 50.3 & 4.37 \\
\hline 50 & 48.2 & 4.56 & 101.4 & 2.17 & 54.9 & 4.00 & 49.0 & 4.49 & 43.0 & 5.11 \\
\hline 60 & 41.8 & 5.26 & 104.5 & 2.10 & 50.1 & 4.39 & 43.4 & 5.07 & 36.4 & 6.04 \\
\hline 70 & 35.7 & 6.16 & 107.5 & 2.05 & 45.0 & 4.89 & 38.0 & 5.79 & 30.7 & 7.16 \\
\hline 80 & 29.6 & 7.43 & 109.8 & 2.00 & 40.1 & 5.48 & 32.8 & 6.71 & 26.1 & 8.43 \\
\hline
\end{tabular}

${ }^{\mathrm{a}}$ Data from ref 32 and $33 .{ }^{\mathrm{b}}$ Data from ref 34.
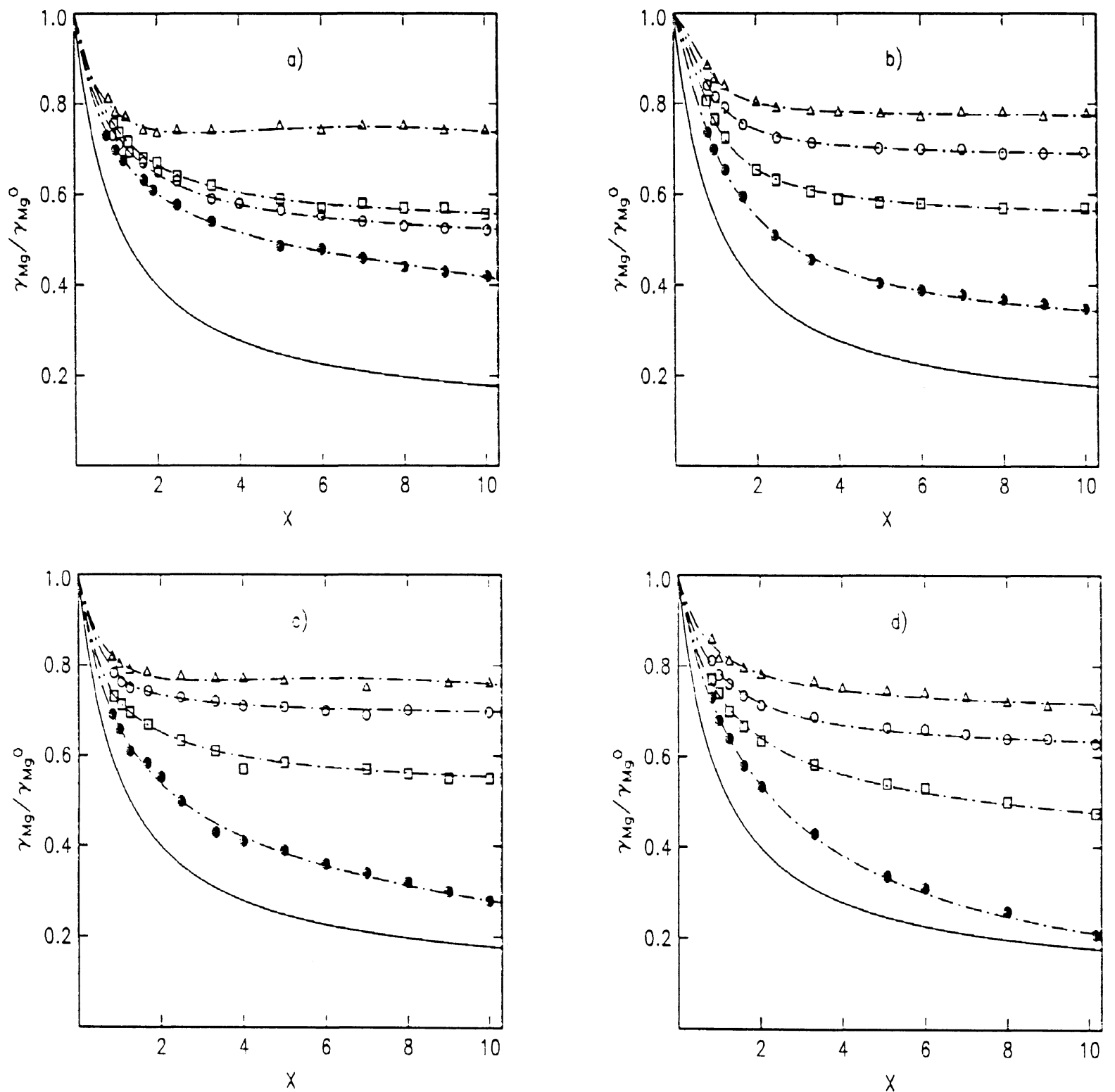

Figure 2. $\mathrm{Mg}^{2+}$ activity coefficients ratios, $\gamma_{\mathrm{Mg}} / \gamma_{\mathrm{Mg}}^{0}$, vs. $X=c_{\mathrm{p}} / c_{2}$ for the system $\mathrm{MgCl}_{2} / \mathrm{MCl} / \mathrm{MDS}$ in different solvents: a) $20 \%$ acetone; b) $20 \%$ methanol; c) $20 \%$ ethanol; d) $20 \% n$-propanol. $c_{\mathrm{p}}=0.002 \mathrm{~mol} \mathrm{dm}^{-3} ; I=0.02 \mathrm{~mol} \mathrm{dm}^{-3} ; \mathrm{MCl}=\mathrm{LiCl}(\bigcirc) ; \mathrm{NaCl}(\bigcirc) ; \mathrm{KCl}(\square) ; \mathrm{CsCl}(\triangle)$. The dashed dotted lines are fit-curves calculated from eq 3 and 4 using $\xi$ as the adjustable parameter. The solid line is calculated from eq 3 and 4 for divalent couterions using the $\xi$-values of Table I. 
in the mixture. For our measurements we use aqueous mixtures of acetone, methanol, ethanol, $n$-propanol, and formamide. Picked values of $\varepsilon_{\mathrm{r}}$ and $\xi$ calculated for these mixtures at $T=25^{\circ} \mathrm{C}$ are listed in Table I. For the mixtures containing acetone, methanol, ethanol and $n$-propanol $\xi$ increases with increasing $w_{\mathrm{o}}$, while for formamide $\xi$ decreases.

In Figures $2 \mathrm{a}-\mathrm{d}$ the activity coefficient ratios, $\gamma_{\mathrm{Mg}} / \gamma_{\mathrm{Mg}}^{0}$, are plotted versus $X=c_{\mathrm{p}} / c_{\mathrm{Mg}}$. The $\mathrm{MCl}$ concentration was adjusted so that the ionic strength, $I$, remains constant by $0.02 \mathrm{~mol} \mathrm{dm}^{-3}$. That is, $c_{\mathrm{Mg}}$ is much smaller than the concentration, $c_{\mathrm{M}}$, of the alkali ions added in excess.

The dielectric constant, $\varepsilon_{\mathrm{r}}$, of the four solvent mixtures is smaller than the dielectric constant of pure water. According to Table I, this means that the real charge density parameter, $\xi$, is larger than 2.8. Manning's and Iwasa's limiting laws predict that the activity coefficient ratios, $\gamma_{\mathrm{Mg}} / \gamma_{\mathrm{Mg}}^{0}$, decrease with increasing $\xi$ when $X$ is constant. The experimental data, however, show the opposite behavior. The lower full lines are the values of $\gamma_{\mathrm{Mg}} / \gamma_{\mathrm{Mg}}^{0}$ as predicted by Manning, while the experimental curves lie above. Interestingly, for the alcohols $\gamma_{\mathrm{Mg}} / \gamma_{\mathrm{Mg}}^{0}$ goes up at constant $X$ as we replace $\mathrm{Li}^{+}$by $\mathrm{K}^{+}$, $\mathrm{K}^{+}$by $\mathrm{Na}^{+}$, or $\mathrm{Na}^{+}$by $\mathrm{Cs}^{+}$. For water/acetone the trend is similar, but the curve for $\mathrm{Na}^{+}$lies below that of $\mathrm{K}^{+}$. That is, for the alcohols we have the ion sequence $\mathrm{Cs}^{+}<\mathrm{Na}^{+}<\mathrm{K}^{+}<\mathrm{Li}^{+}$, while for acetone it holds $\mathrm{Cs}^{+}<\mathrm{K}^{+}<\mathrm{Na}^{+}<\mathrm{Li}^{+}$. The validity of these sequences is of course limited to the region where the mass fraction of the organic solvent, $w_{\mathrm{o}}$, is $20 \%$ or larger. If $w_{\mathrm{o}}$ converges to $0 \%$ (pure water) the trend changes to $\mathrm{Li}^{+}<\mathrm{Na}^{+}<\mathrm{K}^{+}<\mathrm{Cs}^{+}$. This is a quite remarkable result, because it indicates that an ion sequence can be inverted or partly inverted when an organic solvent, such as acetone or methanol, is added to the aqueous solution. Neither Manning's nor Iwasa's limiting laws do predict such a behavior.

Two effects may be important. Firstly, in mixed solvents the solute is preferably solvated by the solvent component by which it interacts more strongly with. It was suggested ${ }^{22}$ that solvation in these media is analogous to complexation, the best solvent taking the role of the ligand. In our case, it leads to changes in the composition of the small ion coordination, or inner solvation sphere, and consequently, it alters the interactions of solvated counterions with the polyions. Secondly, preferential solvation results in a non-random distribution of solvent molecules within the system. The proportions of water and organic solvent molecules in the polyion-counterion condensation region may differ from those in the bulk solvent. Clearly, the dielectric constant, $\varepsilon_{\mathrm{r}}$, at the polyion surface is different from that in the bulk solvent. The latter may be the reason, why for a given $X$ the ratio $\gamma_{\mathrm{Mg}} / \gamma_{\mathrm{Mg}}^{0}$ increases with increasing content of the organic solvent.

There is a third point which is interesting. The amount of hydration is for DP significantly larger than for DS. ${ }^{20}$ At a degree of substitution of 1 the upper hydration number per $\mathrm{PO}_{3}^{-}$-group is of the order of 24 while for $\mathrm{SO}_{3}^{-}$it is 11 . The radii of hydration of the alkali ions decreases in the order $\mathrm{Li}^{+}>\mathrm{Na}^{+}>\mathrm{K}^{+}>\mathrm{Cs}^{+}$. With respect to the ion sequences this means that the polyion with the larger amount of hydration number, i.e., DP, binds preferably the counterion with the largest hydration number, i.e., $\mathrm{Li}^{+}$, while the polyion with the lower amount of hydration, i.e., DS, binds strongest that counterion having the smallest hydration number, i.e., $\mathrm{Cs}^{+}$. In other words, the ionic dextran derivates bind the counterions as far as possible so that they must change only minimal their hydration state. ${ }^{37}$ This is energetically favorable. In a mixed solvent the same principle may be hold, but in addition there is a hydrophobic solvation of the hydrophobic groups of the polyion by the organic solvent component. The latter may be the reason why the ion sequence depends on the kind of the solvent and on the solvent composition. An organic solvent, such as acetone, changes the structure of water in the vicinity of an ionic dextran group so that the resulting local decrease in the dielectric constant of water depresses the dissociation of the ionic group. The dissociation energy of an ion, which has relatively few water molecules of hydration, such as $\mathrm{Cs}^{+}$, would not be extensively affected by the organic (more hydrophobic) medium. The hydration structure of an ion having appreciable water of hydration, such as $\mathrm{Li}^{+}$, must on the other hand be significantly disrupted so as to decrease its hydration energy. This generates an ion selectivity which may be inverse to that of pure water.

In Figures $2 \mathrm{a}-\mathrm{d}$, the experimental data can be well described by Manning's limiting law if the charge density parameter, $\xi$, or the dielectric constant, $\varepsilon_{\mathrm{r}}$, respectively, are considered as fit parameters and adjusted appropriately. The dashed dotted lines in Figure 2 are obtained by such a fit. The appertaining fit values are listed in Table II. We call them $\xi_{\text {eff }}$ and $\varepsilon_{\text {eff }}$, where "eff" stands for effective. The values of $\varepsilon_{\text {eff }}$ are very high, particularly for $\mathrm{Cs}^{+}$. They are all larger than 78 , which is the value for pure water, a result which seems to be unphysically. The reason is that DS changes significantly its conformation in mixed solvents. The poor agreement with theory leading to charge density parameters, $\xi_{\text {eff }}$, lower than 1 might be the result of some folding within the polyion chain. However, there is another problem, concerning the distance, $b$, between two charged groups on the polyion. According to theory we have to use for $b$ the value of the naked polyion, i.e., the value where the polyion is completely dissociated. In mixed solvents the degree of polyion dissociation decreases with increasing content of the organic solvent component. Thus, possibly one must adjust both $b$ and $\varepsilon_{\mathrm{r}}$.

Table II. Adjusted values of $\varepsilon_{\mathrm{r}}$ and $\xi$, called $\varepsilon_{\text {eff }}$ and $\xi_{\text {eff }}$, from measurements of $\gamma_{\mathrm{Mg}} / \gamma_{\mathrm{Mg}}$ for the system $\mathrm{MgCl}_{2} / \mathrm{MDS} / \mathrm{MCl}$ in various water/alcohol mixtures

\begin{tabular}{|c|c|c|c|c|c|c|}
\hline \multirow{2}{*}{$\begin{array}{c}\text { Solvent } \\
\text { M }\end{array}$} & \multicolumn{2}{|c|}{$20 \%$ Methanol } & \multicolumn{2}{|c|}{$20 \%$ Ethanol } & \multicolumn{2}{|c|}{$20 \% n$-Propanol } \\
\hline & $\varepsilon_{\text {eff }}$ & $\xi_{\text {eff }}$ & $\varepsilon_{\text {eff }}$ & $\xi_{\text {eff }}$ & $\varepsilon_{\text {eff }}$ & $\xi_{\text {eff }}$ \\
\hline $\mathrm{Li}$ & 215 & 1.02 & 183 & 1.20 & 163 & 1.35 \\
\hline $\mathrm{Na}$ & 357 & 0.62 & 345 & 0.64 & 317 & 0.69 \\
\hline $\mathrm{K}$ & 457 & 0.48 & 449 & 0.49 & 420 & 0.52 \\
\hline $\mathrm{Cs}$ & 522 & 0.42 & 496 & 0.44 & 485 & 0.45 \\
\hline
\end{tabular}




\section{Counterion Binding}

In Figure 3 the degree of divalent counterion binding, $\theta_{2}$, is plotted versus the concentration ratio $c_{2} / c_{\mathrm{p}}$ for the systems $\mathrm{Ca}^{2+} / \mathrm{Na}^{+} / \mathrm{NaDS} \quad\left((\bigcirc) \quad I=0.01 \mathrm{~mol} \mathrm{dm}{ }^{-3}\right)$, $\mathrm{Cd}^{2+} / \mathrm{Na}^{+} / \mathrm{NaDS}\left((\square) \quad I=0.01 \mathrm{~mol} \mathrm{dm}^{-3}\right.$ and $\left.I=0.05 \mathrm{~mol} \mathrm{dm}^{-3}\right)$, and $\mathrm{Cd}^{2+} / \mathrm{Na}^{+} / \mathrm{Na}_{2} \mathrm{DP}((\triangle) I=$ $0.05 \mathrm{~mol} \mathrm{dm}^{-3}$ ) at $c_{\mathrm{p}}=0.002 \mathrm{~mol} \mathrm{dm}^{-3}$. Here, $\theta_{2}$ is the fraction of bound divalent counterions per charged polyion group, determined via measured activities, $c_{2}$ is the total divalent ion concentration, and $c_{\mathrm{p}}$ is the polyion equivalent concentration. The upper broken line was calculated by simple condensation theory ${ }^{12}$ and the two lower lines by the two variable theory (middle curve $I=0.01 \mathrm{~mol} \mathrm{dm}^{-3}$, lower curve $I=0.05 \mathrm{~mol} \mathrm{dm}^{-3}$ ).

The solvent used was water at $25^{\circ} \mathrm{C}$. Several effects are observed. Firstly, the experimental data show a smooth increase in $\theta_{2}$ with increasing divalent counterion concentration, $c_{2}$. This is in agreement with the two

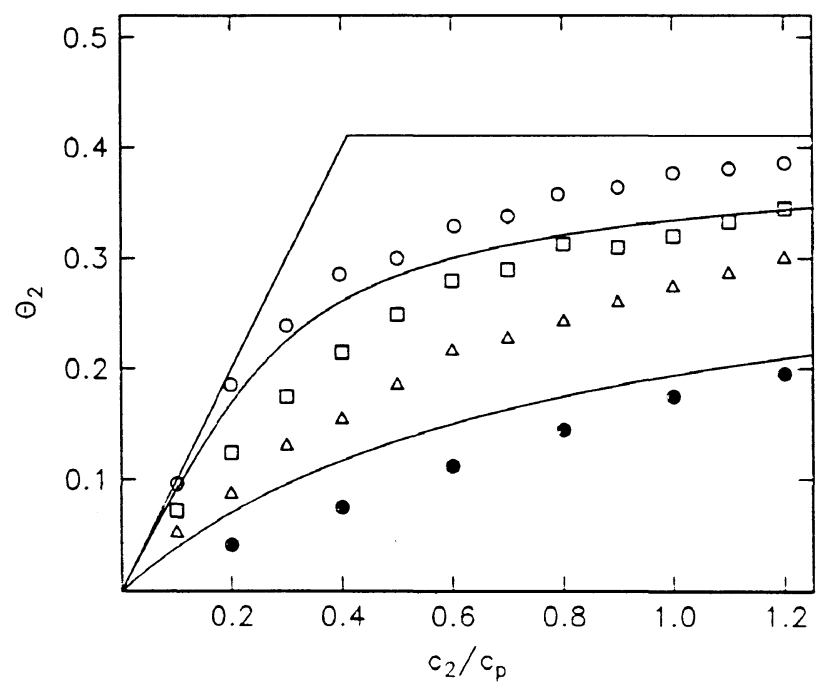

Figure 3. $\theta_{2}$ vs. $c_{2} / c_{\mathrm{p}}$ for the aqueous systems $\mathrm{Ca}^{2+} / \mathrm{Na}^{+} / \mathrm{NaDS}((\mathrm{O})$ $\left.I=0.01 \mathrm{~mol} \mathrm{dm}^{-3}\right) ; \mathrm{Cd}^{2+} / \mathrm{Na}^{+} / \mathrm{NaDS}\left((\square) I=0.01 \mathrm{~mol} \mathrm{dm}^{-3} ;\right.$ $\left.I=0.05 \mathrm{~mol} \mathrm{dm}^{-3}\right)$, and $\mathrm{Cd}^{2+} / \mathrm{Na}^{+} / \mathrm{Na}_{2} \mathrm{DP}\left((\triangle) I=0.05 \mathrm{~mol} \mathrm{dm}^{-3}\right)$. Solid lines, simple condensation theory (upper curve); two variable theory (middle curve, $I=0.01 \mathrm{~mol} \mathrm{dm}^{-3}$; lower curve, $I=0.05$ moldm ${ }^{-3}$ ) with $c_{\mathrm{p}}=0.002 \mathrm{~mol} \mathrm{dm}^{-3}$.

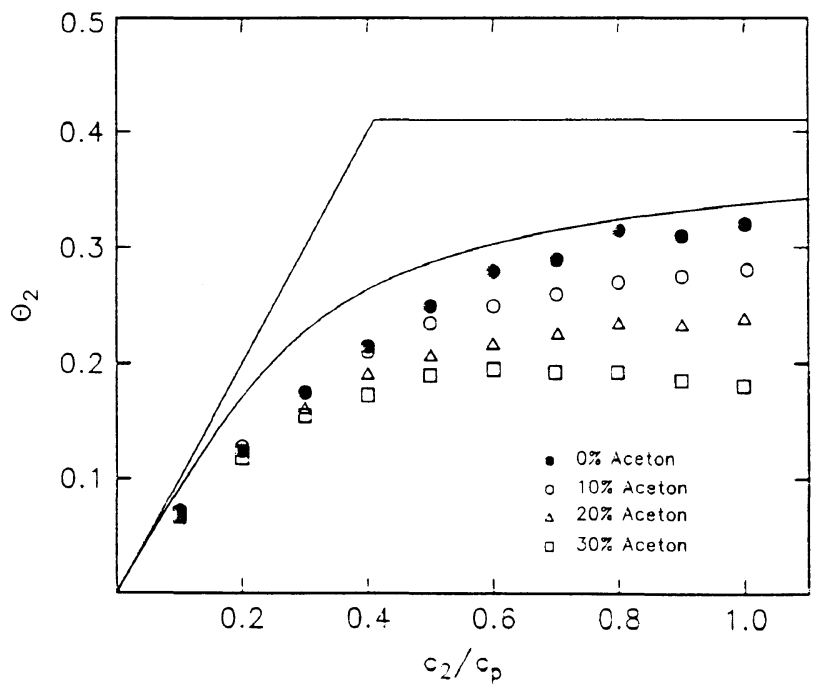

Figure 4. $\theta_{2}$ vs. $c_{2} / c_{\mathrm{p}}$ for the system $\mathrm{Cd}^{2+} / \mathrm{Na}^{+} / \mathrm{NaDS} / \mathrm{K}^{+}$. The solvents are mixtures of water and acetone. Upper solid line: simple condensation theory. Lower solid line, two variable theory; $c_{\mathrm{p}}=$ $2 \times 10^{-3} \mathrm{~mol} \mathrm{dm}^{-3} ; I=0.01 \mathrm{~mol} \mathrm{dm}^{-3} ; \xi=2.8$. variable theory. Secondly, at a given $c_{2} / c_{\mathrm{p}}, \theta_{\mathrm{Ca}^{2}+}$ is slightly larger than $\theta_{\mathrm{Cd}^{2}+}$ as $I=0.01 \mathrm{~mol} \mathrm{dm}^{-3}$. This indicates that $\mathrm{Ca}^{2+}$ ions interact stronger with dextran sulfate than $\mathrm{Cd}^{2+}$ ions do. The reason may be that the ion radius of $\mathrm{Ca}^{2+}$ is smaller than that of $\mathrm{Cd}^{2+}$. Thirdly, at $I=0.05 \mathrm{~mol} \mathrm{dm}^{-3}$, dextran sulfate binds more $\mathrm{Cd}^{2+}$ ions than dextran phosphate does. Clearly, the reason is that the charge density parameter, $\xi$, of DS is 2.8 while that of DP is only 1.6.

Binding isotherms of the system $\mathrm{Cd}^{2+} / \mathrm{Na}^{+} / \mathrm{NaDS}$ dissolved in water/acetone mixtures are presented in Figure 4. Again, the temperature is $25^{\circ} \mathrm{C}, c_{\mathfrak{p}}$ is 0.002 mol dm ${ }^{-3}$ and $I$ is $0.01 \mathrm{~mol} \mathrm{dm}^{-3}$. The solid curves (the upper curve is calculated from the simple condensation theory and the lower curve from the two variable theory) describe $\xi=2.8$, i.e., pure water. We observe that for a given ratio $c_{2} / c_{\mathrm{p}}$, the degree of binding, $\theta_{\mathrm{Cd}^{2+}}$, decreases with increasing mass fraction, $w_{\mathrm{A}}$, of acetone. This is not compatible with theory. Since the dielectric constant, $\varepsilon_{\mathrm{r}}$, of acetone is smaller than that of water, the charge density parameter, $\xi$, becomes larger the larger $w_{\mathrm{A}}$ is. According to theory this means that $\theta_{2}$ should increase with increasing acetone content, but the contrary is observed.
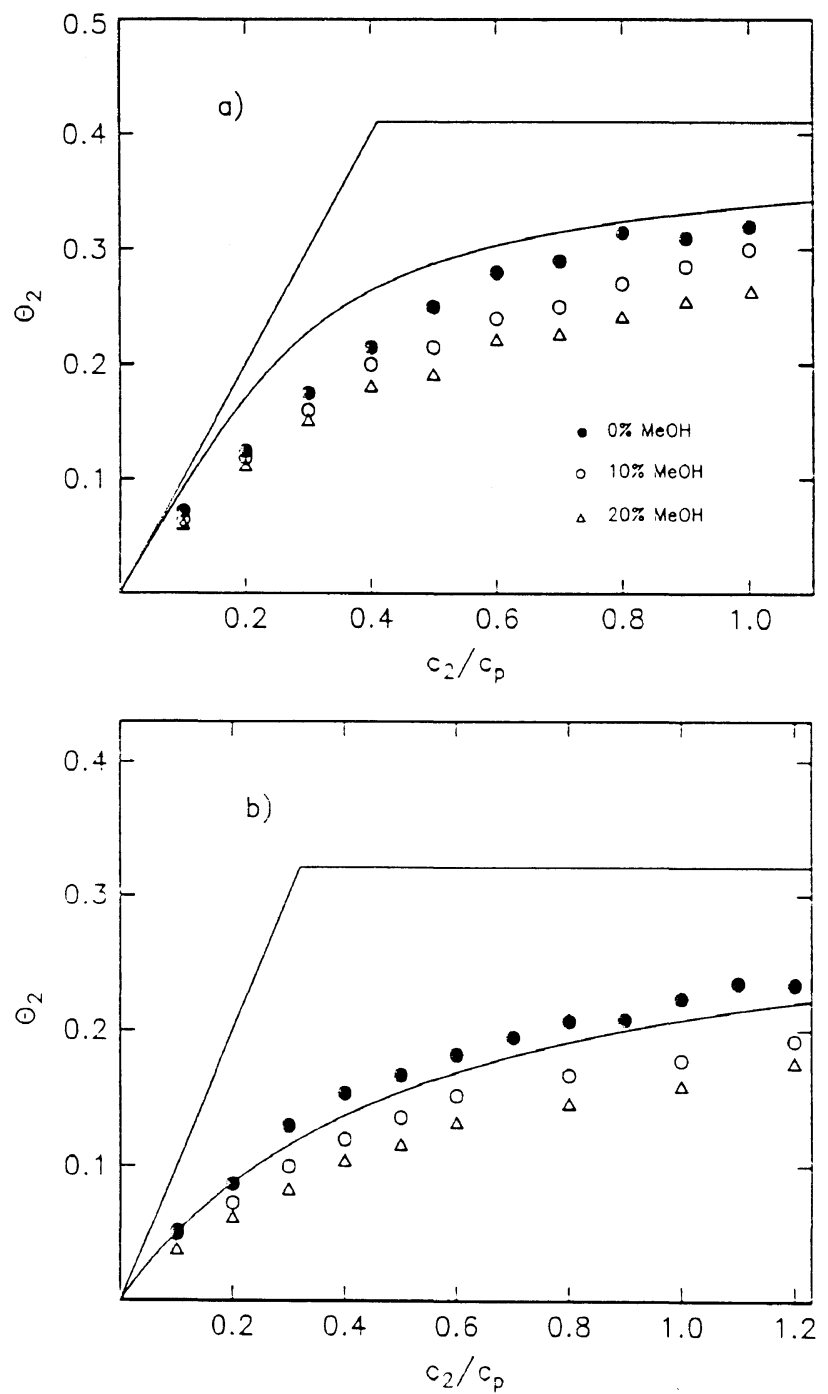

Figure 5. $\theta_{2}$ vs. $c_{2} / c_{\mathrm{p}}$ for the systems: a) $\mathrm{Cd}^{2+} / \mathrm{Na}^{+} / \mathrm{NaDS} / \mathrm{K}^{+}$; $\left.c_{\mathrm{p}}=0.002 \mathrm{~mol} \mathrm{dm}{ }^{-3} ; I=0.01 \mathrm{~mol} \mathrm{dm}^{-3} ; \xi=2.8 . \mathrm{b}\right) \mathrm{Cd}^{2+} / \mathrm{Na}^{+} / \mathrm{Na}_{2} \mathrm{DP} /$ $\mathrm{K}^{+} ; c_{\mathrm{p}}=0.002 \mathrm{~mol} \mathrm{dm}^{-3} ; I=0.02 \mathrm{~mol} \mathrm{dm}^{-3} ; \xi=1.6$. Upper solid lines, simple condensation theory. Lower solid lines, two variable theory. The solvents are mixtures of water and methanol.

Polym. J., Vol. 28, No. 8, 1996 
Table III. Degrees of counterion binding, $\theta_{2}$, of $\mathrm{Mg}^{2+}$ (measured and calculated) for the system $\mathrm{Mg}^{2+} / \mathrm{NaDS} / \mathrm{Na}^{+} /$water/formamide

$\left(c_{\mathrm{p}}=0.002 \mathrm{~mol} \mathrm{dm}^{-3} ; I=0.01 \mathrm{~mol} \mathrm{dm}^{-3}\right.$. $)$

\begin{tabular}{|c|c|c|c|c|c|c|c|c|c|c|}
\hline \multirow{2}{*}{$c_{2} / c_{\mathrm{p}}$} & \multicolumn{5}{|c|}{$\theta_{2}$ (Two variable theory) } & \multicolumn{5}{|c|}{$\theta_{2}$ (Experiment) } \\
\hline & $0 \%$ & $10 \%$ & $20 \%$ & $30 \%$ & $40 \%$ & $0 \%$ & $10 \%$ & $20 \%$ & $30 \%$ & $40 \%$ \\
\hline 0.1 & 0.092 & 0.092 & 0.092 & 0.092 & 0.092 & 0.093 & 0.069 & 0.055 & 0.056 & 0.051 \\
\hline 0.2 & 0.170 & 0.169 & 0.169 & 0.168 & 0.168 & 0.157 & 0.142 & 0.104 & 0.100 & 0.094 \\
\hline 0.3 & 0.226 & 0.224 & 0.223 & 0.221 & 0.220 & 0.200 & 0.207 & 0.149 & 0.140 & 0.131 \\
\hline 0.4 & 0.262 & 0.259 & 0.256 & 0.254 & 0.252 & 0.235 & 0.227 & 0.186 & 0.183 & 0.159 \\
\hline 0.5 & 0.285 & 0.281 & 0.278 & 0.275 & 0.272 & 0.261 & 0.262 & 0.219 & 0.217 & 0.190 \\
\hline 0.6 & 0.301 & 0.296 & 0.293 & 0.289 & 0.286 & 0.280 & 0.301 & 0.248 & 0.240 & 0.213 \\
\hline 0.7 & 0.313 & 0.308 & 0.304 & 0.300 & 0.297 & 0.301 & 0.320 & 0.270 & 0.265 & 0.239 \\
\hline 0.8 & 0.322 & 0.316 & 0.312 & 0.309 & 0.305 & 0.320 & 0.334 & 0.301 & 0.309 & 0.259 \\
\hline 0.9 & 0.329 & 0.323 & 0.319 & 0.315 & 0.312 & 0.329 & 0.350 & 0.311 & 0.322 & 0.275 \\
\hline 1.0 & 0.335 & 0.329 & 0.325 & 0.321 & 0.318 & 0.340 & 0.370 & 0.330 & 0.340 & 0.298 \\
\hline 1.1 & 0.340 & 0.334 & 0.330 & 0.326 & 0.323 & 0.350 & 0.380 & 0.350 & 0.345 & 0.302 \\
\hline 1.2 & 0.345 & 0.339 & 0.334 & 0.330 & 0.327 & 0.360 & 0.393 & 0.355 & 0.342 & 0.317 \\
\hline
\end{tabular}

Similar results are obtained for other mixed solvents, both for DS and for DP. Two examples are shown in Figures $5 \mathrm{a}$ and $5 \mathrm{~b}$. The solvents are mixtures of water and methanol. Figure 5a presents the binding isotherms of the system $\mathrm{Cd}^{2+} / \mathrm{Na}^{+} / \mathrm{DS}$ where $c_{\mathrm{p}}=0.002 \mathrm{~mol} \mathrm{dm}^{-3}$ and $I=0.01 \mathrm{~mol} \mathrm{dm}^{-3}$. Figure $5 \mathrm{~b}$ shows the results of the system $\mathrm{Cd}^{2+} / \mathrm{Na}^{+} / \mathrm{DP}$ where $c_{\mathrm{p}}=0.002 \mathrm{~mol} \mathrm{dm}^{-3}$ and $I=0.02 \mathrm{~mol} \mathrm{dm}^{-3}$. The solid curves are again the results from theory, calculated for $\xi=2.8$ and $\xi=1.6$, respectively. As in the case of water/acetone, $\theta_{2}$ decreases as the mass fraction, $w_{\mathrm{o}}$, of the organic solvent (methanol) increases. The dielectric constant, $\varepsilon_{\mathrm{r}}$, of methanol is again smaller than the dielectric constant of water. However, there exist also solvents whose dielectric constants are larger than that of water. Formamide is one of the best examples. Theory predicts that in a mixture of water and formamide $\theta_{2}$ should decrease with increasing formamide content. We have proven and confirmed this using the system $\mathrm{Mg}^{2+} / \mathrm{Na}^{+} / \mathrm{NaDS}$ (see Table III).

The experimental $\theta_{2}$ values were determined by means of dye spectroscopy; the theoretical values of $\theta_{2}$ were calculated from the two variable theory, using for $\varepsilon_{\mathrm{r}}$ the value of the salt free solvent mixture at $T=25^{\circ} \mathrm{C}$. Two cases can be distinguished. If $c_{2} / c_{\mathrm{p}}<0.5, \theta_{2}$ decreases with increasing mass fraction, $w_{\mathrm{F}}$, of formamide. This is in qualitative agreement with theory, but the quantitative agreement is rather poor. If $c_{2} / c_{\mathrm{p}}>0.5, \theta_{2}$ first increases with $w_{\mathrm{F}}$ up to $w_{\mathrm{F}} \approx 10 \%$ and then it decreases. We are not able to explain this effect. However, it seems that there is no unquivocal correlation between the degree of divalent counterion binding, $\theta_{2}$, and the dielectric constant, $\varepsilon_{\mathrm{r}}$, of the solvent. For DS and DP $\theta_{2}$ decreases as the mass fraction of the organic component increases irrespective whether $\varepsilon_{\mathrm{r}}$ decreases or not. On the other hand, there are also experiments with mixed solvents that are in qualitative agreement with theory. $\mathrm{Volmer}^{23}$ observed for polystyrenesulfonate a decrease of $\theta_{2}$ as $\varepsilon_{\mathrm{r}}$ increases and vice versa. Thus, we have a puzzling situation.

Next, we turn our attention to the influence of the nature of the univalent counterion (added in excess) on the degree of divalent counterion binding in a mixed solvent. Obviously, such an influence is not incorporated into theory.
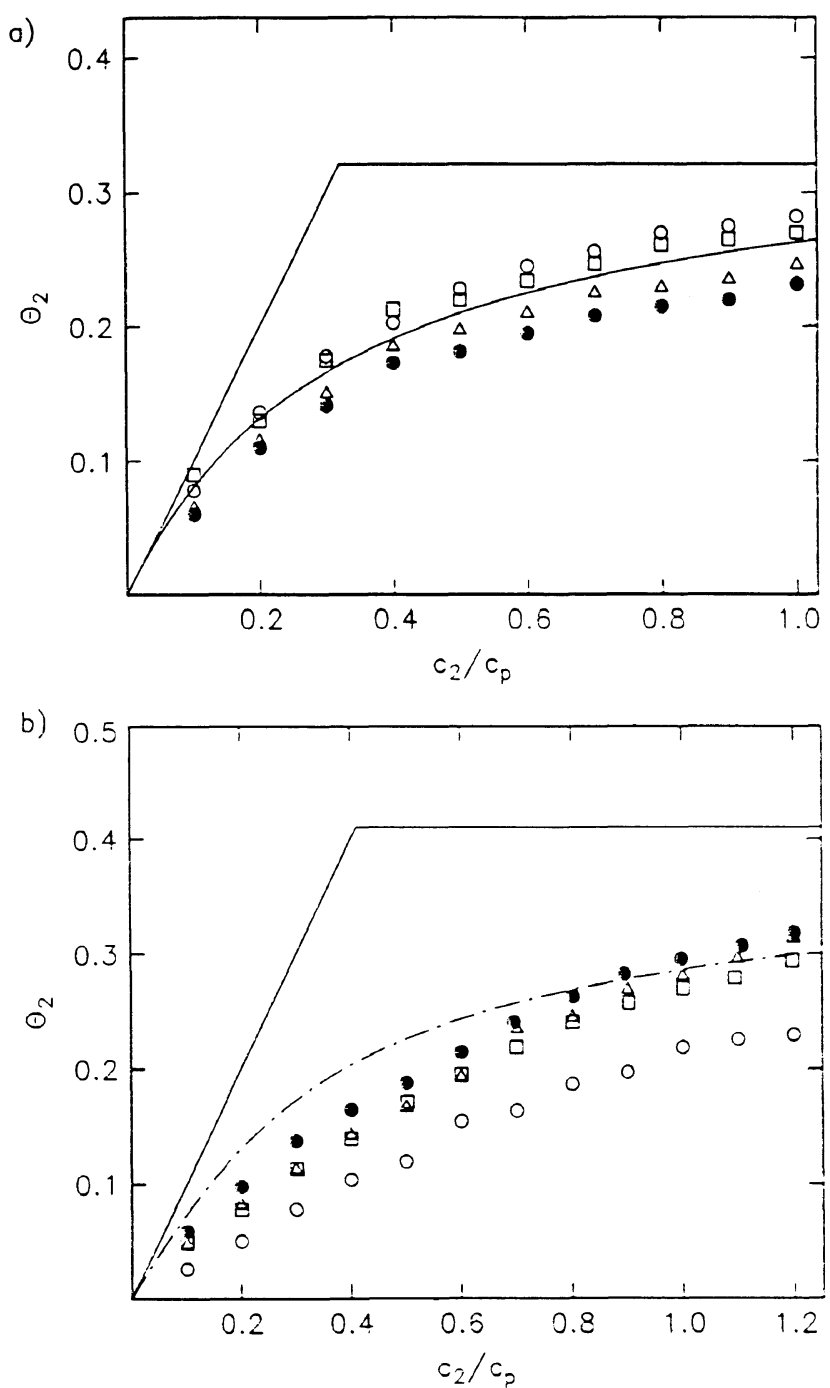

Figure 6. $\theta_{2}$, vs. $c_{2} / \mathrm{c}_{\mathrm{p}}$ for the systems: a) $\mathrm{MgCl}_{2} / \mathrm{MCl} / \mathrm{M}_{2} \mathrm{DP} ; \mathrm{b}$ ) $\mathrm{MgCl}_{2} / \mathrm{MCl} / \mathrm{MDS}$. The solvents are mixtures of water and acetone $(80 / 20) . c_{\mathrm{p}}=0.002 \mathrm{~mol} \mathrm{dm}^{-3} ; I=0.01 \mathrm{~mol} \mathrm{dm}^{-3} ; \mathrm{MCl}=\mathrm{LiCl}(\bullet) ; \mathrm{NaCl}$ $(\triangle) ; \mathrm{KCl}(\square) ; \mathrm{CsCl}(\bigcirc)$. Theoretical curves (full lines) are mentioned as before.

Figures $6 \mathrm{a}$ and $6 \mathrm{~b}$ show the binding isotherms of the systems $\mathrm{MgCl}_{2} / \mathrm{MCl} / \mathrm{M}_{2} \mathrm{DP}$ and $\mathrm{MgCl}_{2} / \mathrm{MCl} / \mathrm{MDS}$, where $\mathrm{M}$ stands for the alkali metals: $\mathrm{Li}(\bullet), \mathrm{Na}(\triangle)$, $\mathrm{K}(\square)$, and Cs $(\mathrm{O})$. The solvent is a mixture containing 

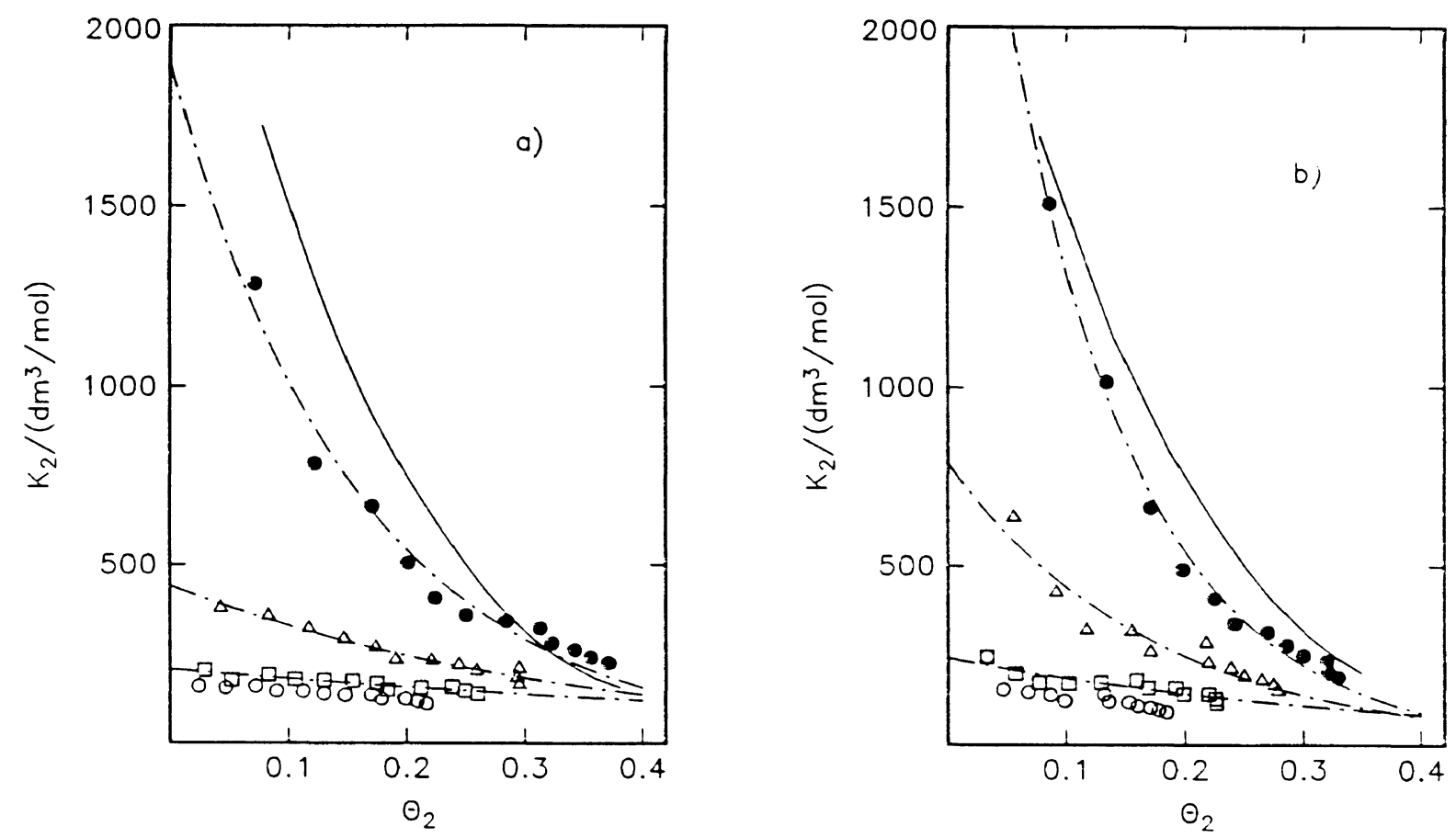

Figure 7. Plots of $K_{2}$ vs. $\theta_{2}$ for the system $\mathrm{MgCl}_{2} / \mathrm{MCl} / \mathrm{MDS}$ dissolved in various solvents: a) $20 \%$ ethanol; b) $20 \%$-propanol. $c_{\mathrm{p}}=0.002 \mathrm{~mol}$ dm ${ }^{-3}$; $I=0.02$ moldm${ }^{-3} ; \mathrm{MCl}=\mathrm{LiCl}(\bigcirc) ; \mathrm{NaCl}(\triangle) ; \mathrm{KCl}(\square) ; \mathrm{CsCl}(\bigcirc)$. Full lines, calculated by Manning; dashed lines, least square fit.

$80 \%$ water and $20 \%$ acetone at $T=25^{\circ} \mathrm{C}$. The polyion concentration is kept constant at $0.002 \mathrm{~mol} \mathrm{dm}^{-3}$. We observe that, at a higher ratio $c_{2} / c_{\mathrm{p}}$, the degree of binding, $\theta_{2}$, of $\mathrm{Mg}^{2+}$ to dextran phosphate, increases with decreasing radius of hydration of the univalent cations: $\theta_{2} \quad\left(\mathrm{Cs}^{+}\right)>\theta_{2} \quad\left(\mathrm{~K}^{+}\right)>\theta_{2} \quad\left(\mathrm{Na}^{+}\right)>\theta_{2} \quad\left(\mathrm{Li}^{+}\right)$, while the sequence deduced for dextran sulfate is inverse. This can be explained that for DP the smaller hydrated $\mathrm{Cs}^{+}$ions can be more easily displaced by $\mathrm{Mg}^{2+}$ ions than the larger hydrated ions $\mathrm{K}^{+}, \mathrm{Na}^{+}$, or $\mathrm{Li}^{+}$. Thus, we find the following univalent counterion binding sequence: $\mathrm{Li}^{+}>$ $\mathrm{Na}^{+}>\mathrm{K}^{+}>\mathrm{Cs}^{+}$for DP, and $\mathrm{Li}^{+}<\mathrm{Na}^{+}<\mathrm{K}^{+}<\mathrm{Cs}^{+}$for $\mathrm{DS}$. The order of these sequences does not change when altering the solvent. For water/alcohol mixtures, the same sequences are obtained as for pure water. They are identical with those where no $\mathrm{Mg}^{2+}$ is present. This indicates that ion binding to dextran sulfate takes place with retention of the hydration layers on the alkali ions, while for dextran phosphate the alkali ions lose a part of their hydration shells. Presumably, alkali ions will be bound delocalized by DS and localized, i.e., by site binding, by DP.

The above results are consistent with the results of our activity measurements. Nevertheless, there is a small difference. Comparison of Figures 2 and 6 shows that depending on the solvent, the binding selectivity is differently pronounced. In water/alcohol mixtures the averate difference between $\theta_{2}\left(\mathrm{Li}^{+}\right)$and $\theta_{2}\left(\mathrm{Cs}^{+}\right)$is twice as large as for water/acetone mixtures. That is, nonCoulombic interactions between the polyion and the hydrated univalent cations play an important role.

The experimental results can also be presented in the form of Scatchard-plots. These are plots where $K_{2} \equiv$ $\theta_{2} / c_{2 \mathrm{f}}$ is plotted versus $\theta_{2}$, where $c_{2 \mathrm{f}}$ denotes the concentration of the free divalent cations and $K_{2}$ the equilibrium constant for the transfer of divalent counterion from the bulk solution to the volume, $V_{\mathrm{c}}$, around the polyion in which the counterions are mobile but delocalized bound. Two examples are shown in Figures $7 \mathrm{a}$ and $7 \mathrm{~b}$.

The temperature is kept constant at $25^{\circ} \mathrm{C}$, the polyion concentration is $0.002 \mathrm{~mol} \mathrm{dm}^{-3}$, and the ionic strength is $0.02 \mathrm{~mol} \mathrm{dm}^{-3}$. The solid lines are calculated from the two variable theory and the dashed dotted lines are simple polynomial fits. Agreement between theory and experiment is qualitatively sufficient. $K_{2}$ decreases with increasing $\theta_{2}$, indicating the anticooperative nature of the counterion binding, as was previously observed for other polyelectrolytes in pure water. ${ }^{24,25}$ However, the quantitative agreement is unsatisfactory. The difference between the theoretical and experimental $K_{2}$ values is less than a factor of 2 for $\mathrm{LiCl}$ and increases up to a factor of 5 for $\mathrm{KCl}$ and $\mathrm{CsCl}$ if $\theta_{2}$ is sufficiently small. For higher $\theta_{2}$, the $K_{2}$ values come to lie on one curve. These findings are similar to what has been reported for the interaction of alkali ions with polystyrenesulfonate. ${ }^{23}$

\section{Anomaly in Counterion Condensation Theory}

Figure 8 shows plots of the degree of divalent counterion binding, $\theta_{2}$, versus the dielectric constant $\varepsilon_{\mathrm{r}}$. The $\theta_{2}$ values are calculated by eq 13 and $14 ; I$ is 0.02 mol dm ${ }^{-3}, c_{\mathrm{p}}$ is $0.002 \mathrm{~mol} \mathrm{dm}^{-3}$, and $c_{2} / c_{\mathrm{p}}$ is varied from 0.1 to 1.2. The curves possess the shape of inverse parabels. For $\varepsilon_{\mathrm{r}}=0, \theta_{2}$ converges to zero. At small values of $\varepsilon_{\mathrm{r}}, \theta_{2}$ increases with increasing $\varepsilon_{\mathrm{r}}$. If $\varepsilon_{\mathrm{r}} \gg 0$, first $\theta_{2}$ passes through a maximum and then decreases. That is, for any value of $\theta_{2}$ there exist two corresponding values of $\varepsilon_{\mathrm{r}}$. This phenomenon is observed only if we calculate $\theta_{2}$ or $\theta_{1}$. Calculating $\varepsilon_{\mathrm{r}}$ from eq 3 and 4 using the activity coefficients we obtain one value of $\varepsilon_{\mathrm{r}}$ for each value of $\gamma_{ \pm}$. Therefore, we call this phenomenon an anomaly in condensation theory. It has interesting consequences. In the chapter activity coefficients, we have handled $\varepsilon_{\mathrm{r}}$ as an adjustable parameter. This gave quite good fit-curves 


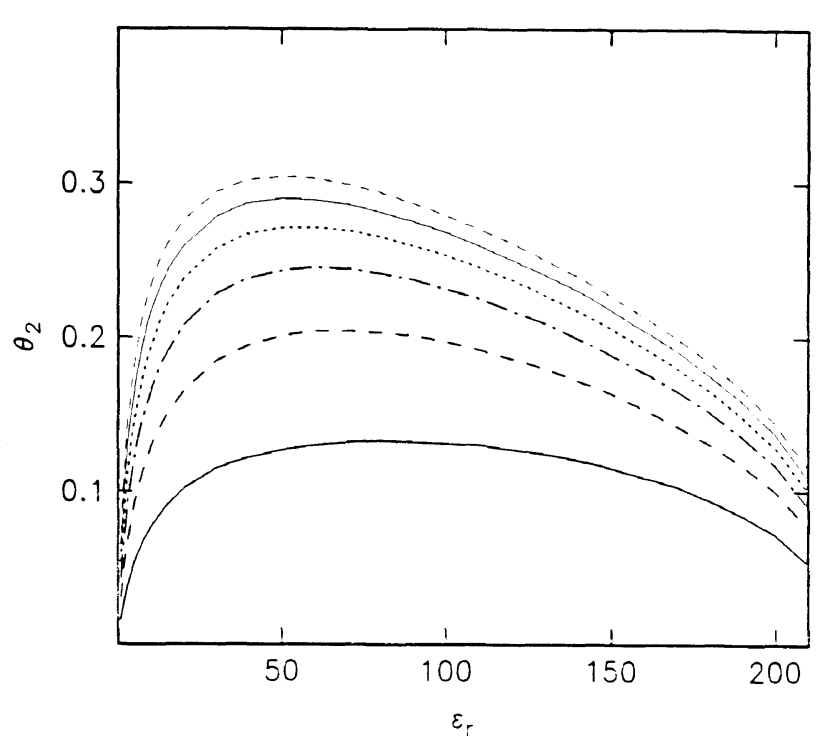

Figure 8. Theoretical $\theta_{2}$ values, calculated from eq 13 and $14, v s . \varepsilon_{\mathrm{r}}$ for different $c_{2} / c_{\mathrm{p}}$ ratios. From above to the bottom: $c_{2} / c_{\mathrm{p}}=1.2,1.0$, $0.8,0.6,0.4$, and 0.2 . The ionic strength is $I=0.02 \mathrm{~mol} \mathrm{dm}^{-3}$.

for the results of measurements. Such an adjustment can be also performed for $\theta_{2}$. However, in contrast to the activity coefficients, now we get a pair of $\varepsilon_{\mathrm{r}}$ values where both $\varepsilon_{\mathrm{r}}$-values fit the experimental values of $\theta_{2}$ similarly well. Such a pair of $\varepsilon_{\mathrm{r}}$ values consists of a low and a high value. We call them $\varepsilon_{\mathrm{r} 1}$ and $\varepsilon_{\mathrm{r} 2}$, where the dielectric constant, $\varepsilon_{\mathrm{r}}$, of the solvent lies between these two values (see Table IV).

For instance, the fit values of $\varepsilon_{\mathrm{r}}$ for the system $\mathrm{MgCl}_{2} / \mathrm{MCl} / \mathrm{MDS}$ dissolved in $20 \%$ methanol are 7 and 180 , while the $\varepsilon_{\mathrm{r}}$-value of the solvent mixture is 67 . This leads to the question for the most realistic value of $\varepsilon_{\mathrm{r}}$. $\theta_{2}$ describes the degree of divalent counterion binding of the condensed counterions near the polyion surface. The dielectric constant of dextran is of the order of 4 . Therefore, the dielectric constant of the solvent should decrease from $\varepsilon_{\mathrm{r}}=67$ in the polyion free region to $\varepsilon_{\mathrm{r}}=4$ at the polyion surface. For this reason we believe that the smaller value of $\varepsilon_{\mathrm{r}}$, i.e., $\varepsilon_{\mathrm{r} 1}=7$, is the more realistic one.

From Table IV we see that $\varepsilon_{\mathrm{r} 1}$ decreases from $\mathrm{Li}^{+}$to $\mathrm{Cs}^{+}$. This may be interpreted as follows. The average distance between a territorial bound $\mathrm{Mg}^{2+}$ ion and the polyion surface is relatively large in the presence of $\mathrm{Li}^{+}$ ions and small in the presence of $\mathrm{Cs}^{+}$ions. That means, a $\mathrm{Mg}^{2+}$ ion is weaker bound in the presence of $\mathrm{Li}^{+}$ions than in the presence of $\mathrm{Cs}^{+}$ions. This holds for the major part of cases of solvent mixtures we have studied.

The Poisson-Boltzmann Equation and Counterion Binding

We have seen that counterion binding to DS and to DP in mixed solvents is not in agreement with the predictions of condensation theory. The reason may be that the Manning theory is the first step in a series of approximations for which the Poisson-Boltzmann equa$\operatorname{tion}^{26}$ is the second. Thus, we may get new insights if we solve the Poisson-Boltzmann equation for the case of mixed solvents and compare the results with those of condensation theory and experiment.

The model is again a long polyion cylinder of radius,
Table IV. Adjusted dielectric constants obtained from measurements of $\theta_{2}$ for the system $\mathrm{MgCl}_{2} / \mathrm{MDS} / \mathrm{MCl}$ dissolved in various water/alcohol mixtures

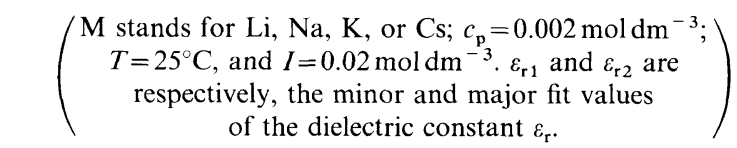

\begin{tabular}{|c|c|c|c|c|c|c|}
\hline \multirow{2}{*}{$\begin{array}{c}\text { Solvent } \\
\mathrm{M}\end{array}$} & \multicolumn{2}{|c|}{$20 \%$ Methanol } & \multicolumn{2}{|c|}{$20 \%$ Ethanol } & \multicolumn{2}{|c|}{$20 \% n$-Propanol } \\
\hline & $\varepsilon_{\mathrm{r} 1}$ & $\varepsilon_{\mathrm{r} 2}$ & $\varepsilon_{\mathrm{r} 1}$ & $\varepsilon_{\mathrm{r} 2}$ & $\varepsilon_{\mathrm{r} 1}$ & $\varepsilon_{\mathrm{r} 2}$ \\
\hline $\mathrm{Li}$ & 40 & 70 & 40 & 70 & 60 & 60 \\
\hline $\mathrm{Na}$ & 15 & 145 & 15 & 145 & 20 & 150 \\
\hline $\mathrm{K}$ & 7 & 180 & 8 & 190 & 9 & 195 \\
\hline Cs & 4 & 200 & 6 & 210 & 5 & 200 \\
\hline
\end{tabular}

$a$, having $N$ charges on its surface. The axial distance between two charged groups on the polyion is $b$. Thus, the length of the cylinder is $N b$. The polyion is located on the axis of a large cylindrical volume of outer radius $R_{\mathrm{c}}$. Between the fixed surfaces, $a$ and $R_{\mathrm{c}}$, there are $N_{\mathrm{c}}$ mobile counterions and $N_{\text {co }}$ mobile coions, as well as solvent. The small ions are delocalized bound to the polyion, i.e., the counterions are attracted by the polyion potential and the coions by the counterions so that both types of ions may be considered as bound to the polyion. According to Manning ${ }^{12}$ the volume $V_{\mathrm{c}}=\pi b\left(R_{\mathrm{c}}^{2}-a^{2}\right)$ may be called condensation volume. However, there is a significant difference between our model and Manning's. In our model, coions are allowed to be within $V_{\mathrm{c}}$, while by Manning they are not. The cylinder of radius, $R_{\mathrm{c}}$, is located on the axis of a much larger cylinder of radius $R_{\mathrm{o}}$. The counterions and the coions between the cylinder surfaces, $R_{\mathrm{c}}$ and $R_{\mathrm{o}}$, are free. They are not bound, i.e., their diffusion velocities are not correlated with that of the polyion. According to Manning ${ }^{12}$ the volume $V_{\mathrm{DH}}=\pi b\left(R_{\mathrm{o}}{ }^{2}-R_{\mathrm{c}}^{2}\right)$ is identical with the Debye-Hückel region per fixed polyion charge. Furthermore, we assume that the total charge between $a$ and $R_{\mathrm{o}}$ is zero, where $R_{\mathrm{o}}$ is finite.

Now, the Poisson-Boltzmann equation for our model can be formulated. If $r \equiv a x$ is the distance from the polyion axis, where $x \geq 0$ is a dimensionless number, and $y \equiv-e \psi / k_{\mathrm{B}} T$ is the reduced potential, with $\psi$ being the electrostatic potential at $r, e$ the elementary charge, and $k_{\mathrm{B}} T$ as usual, we have

$$
\frac{\mathrm{d}^{2} y}{\mathrm{~d} x^{2}}+\frac{1}{x} \frac{\mathrm{d} y}{\mathrm{~d} x}=4 \pi a^{2} \xi b \sum_{i} z_{i} c_{i, 0} \exp \left(z_{i} y\right)
$$

where $z_{i}$ and $c_{i, 0}$ are the valence and total concentration of the small ions of type $i$. Our solutions contain polyions of concentration $c_{\mathrm{p}}, \mathrm{MgCl}_{2}$ of concentration $c_{2}$, and $\mathrm{MCl}$ of concentration $c_{\mathrm{s}}$, where $\mathrm{M}$ is an alkali metal. Thus, the concentration, $c_{1,0}$, of the univalent counterions is $c_{1,0}=c_{\mathrm{p}}+c_{\mathrm{s}}$, the concentration, $c_{2,0}$, of the divalent ions is $c_{2}$, and the concentration, $c_{3,0}$, of the coions $\left(\mathrm{Cl}^{-}\right)$is $c_{3,0}=c_{\mathrm{s}}+2 c_{2}$. Additionally, two boundary conditions have to be fulfilled. Due to the Gauss's law, it holds

$$
\begin{aligned}
& \left.\frac{\mathrm{d} y}{\mathrm{~d} x}\right|_{x=1}=-2 \xi \\
& y\left(R_{\mathrm{o}} / a\right)=0
\end{aligned}
$$


As far as we know, no one has ever solved analytically the Poisson-Boltzmann equation for the case of added salt, but several tables and graphs of numerically obtained solutions have been published. ${ }^{27,28} \mathrm{We}$ ourselves proceed as follows. Firstly, we set $R_{\mathrm{o}}=u \cdot \kappa^{-1}$, where $\kappa^{-1}$ is the Debye screening length and $u$ an arbitrary dimensionless number of the order of 10 . This is allowed since $y(x)$ does not depend sensibly on $R_{\mathrm{o}}$. Secondly, we solve the Poisson-Boltzmann equation, ${ }^{21}$ using the fourth-order Runge-Kutta method. ${ }^{29}$ Thereby, we start with an initial value for $y(x=1)$. If eq 22 and 23 are not fulfilled this value $y(x=1)$ is changed and the evaluation procedure is repeated until satisfaction. The result of these calculations is $y(x)$, the reduced potential.

The concentration, $c_{i}(x)$, of the small ions of type $i$ at the distance $x$ from the polyion axis is

$$
c_{i}(x)=c_{i}\left(R_{\mathrm{o}} / a\right) \exp \left[z_{i} y(x)\right]
$$

with $i=1,2$, and 3 . The fraction, $\theta_{i}$, of ions of type $i$ that are bound (trapped within $V_{\mathrm{C}}$ ) per polyion charge is given by

$$
\theta_{i}=\frac{c_{i, \mathrm{~b}}}{c_{\mathrm{p}}}=\frac{c_{i, 0}}{c_{\mathrm{p}}} \cdot \frac{\int_{1}^{1+\left(R_{\mathrm{c}}-a\right) / a} x \exp \left[z_{i} y(x)\right] \mathrm{d} x}{\int_{1}^{R_{\mathrm{o}} / a} x \exp \left[z_{i} y(x)\right] \mathrm{d} x},
$$

where $c_{i, \mathrm{~b}}$ is the concentration of bound ions of type $i$. The integrations of eq 25 can be performed using the Romberg method. ${ }^{29}$ Figure 9 shows a typical plot of $y$ versus $x=r / a$ for the system $\mathrm{MgCl}_{2} / \mathrm{NaCl} / \mathrm{NaDS} . c_{\mathrm{p}}$ is $0.002 \mathrm{~mol} \mathrm{dm}^{-3}, I$ is $0.02 \mathrm{~mol} \mathrm{dm}^{-3}$, and the solvent is a mixture containing $80 \%$ water and $20 \%$ formamide $(\xi=2.43)$. The radius $a$ of the polyion cylinder was chosen to be $0.5 \mathrm{~nm}$. We see that $y(x)$ is a rapidly decreasing function of $x$. For small values of $x$ the decrease increment is stronger the larger $c_{2} / c_{\mathrm{p}}$ is. This observation is in accord with the results of other workers (see for instance Dolar and Peterlin ${ }^{30}$ ).

The mean topic of this section is the determination of $\theta_{i}$, the degree of counterion binding of type $i$. In order to calculate $\theta_{i}$ by means of eq 25 , we need a value of the

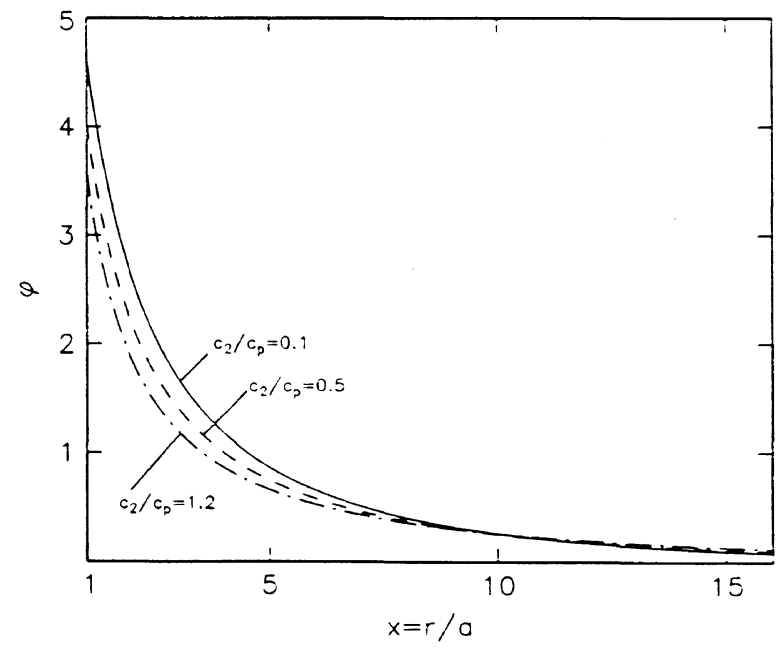

Figure 9. Solutions of the Poisson-Boltzmann equation for a cylinder with $R_{\mathrm{o}} / a=31$. The system is $\mathrm{NaDS} / \mathrm{MgCl}_{2} / \mathrm{NaCl}$ in a mixture of $20 \%$ formamide and $80 \%$ water. $\xi=2.43 ; c_{\mathrm{p}}=0.002 \mathrm{~mol} \mathrm{dm}^{-3} ; \quad I=0.02$ mol dm ${ }^{-3} \cdot c_{2}$ increases from above downwards. radius, $R_{\mathrm{c}}$, of the cylinder which encloses the counterions bound to the polyion. Unfortunately, $R_{\mathrm{c}}$ is not known. Therefore, we proceed as follows. We use $R_{\mathrm{c}}$ as an adjustable parameter. That is, we insert the experimentally derived values of $\theta_{2}$ into eq 25 and determine $R_{\mathrm{c}}$ by the method of least squares. However, we should point out the following. An ionselective electrode measures the activity of simple ions which are completely free. That is, an application of eq 16 is correct for the Manning model where there are two kinds of counterions, completely bounded ions and completely free ones. In the Poisson-Boltzmann model, on the other hand, the small ions distribute around the polyion with continuous decrease in concentration. That is, the activities measured by electrodes are activities at $R_{0}$. In other words, we cannot combine eq 16 with eq 25 , there is no experimental evidence for the position of $R_{\mathrm{c}}$. For this reason the Poisson-Boltzmann analysis is done for the system $\mathrm{MgCl}_{2} / \mathrm{NaCl} / \mathrm{NaDS}$, where the degree of $\mathrm{Mg}^{2+}$. counterion binding were determined by dye-spectroscopy, a method from which we believe that it yields nearly correct the content of counterions bounded exclusively in $V_{\mathrm{c}}$.

Table $\mathrm{V}$ shows some $R_{\mathrm{c}}-a$ values together with $\theta_{2, \exp }$ $\left(c_{\mathrm{p}}\right.$ is $0.002 \mathrm{~mol} \mathrm{dm}^{-3}$ ). The solvents considered are mixtures of water and methanol where the methanol fraction is varied between 0 and $20 \%$. Two effects are observed. Firstly, at a given mass fraction of methanol, $\left(R_{\mathrm{c}}-a\right)$ increases with increasing $c_{2} / c_{\mathrm{p}}$, i.e., with increasing divalent counterion concentration $\left(c_{\mathrm{p}}\right.$ is constant). For the limit $c_{2} \rightarrow 0,\left(R_{\mathrm{c}}-a\right)$ converges to 0 , i.e., $R_{\mathrm{c}}$ converges to $a$ (see eq 25 ). That is, the volume, $V_{\mathrm{c}}=$ $\pi b\left(R_{\mathrm{c}}{ }^{2}-a^{2}\right)$, enclosing the bound counterions is a function of divalent counterion concentration. This is contrary to the predictions of condensation theory where $V_{\mathrm{c}}$ depends only on $\xi$ but neither on $c_{\mathrm{s}}$ nor on $c_{2}$. Secondly, at a given ratio $c_{2} / c_{\mathrm{p}}$, the cylinder radius, $R_{\mathrm{c}}$, decreases as the content of methanol increases. Simultaneously, $\theta_{2, \exp }$ decreases while $\xi$ increases. The question is whether these radii are physically realistic or not. To

Table V. Deduced $\left(R_{\mathrm{c}}-a\right)$ values for the system $\mathrm{MgCl}_{2} / \mathrm{NaDS} / \mathrm{NaCl}$ in various water/methanol mixtures

\begin{tabular}{|c|c|c|c|c|c|c|}
\hline \multirow{4}{*}{$c_{2} / c_{\mathrm{p}}$} & \multicolumn{6}{|c|}{ Mass fraction of methanol } \\
\hline & \multicolumn{2}{|c|}{$0 \%$} & \multicolumn{2}{|c|}{$10 \%$} & \multicolumn{2}{|c|}{$20 \%$} \\
\hline & \multirow{2}{*}{$\theta_{2, \exp }$} & $R_{\mathrm{c}}-a$ & \multirow{2}{*}{$\theta_{2, \exp }$} & \multirow{2}{*}{$\frac{R_{\mathrm{c}}-a}{\mathrm{~nm}}$} & \multirow{2}{*}{$\theta_{2, \exp }$} & \multirow{2}{*}{$\frac{R_{\mathrm{c}}-a}{\mathrm{~nm}}$} \\
\hline & & $\mathrm{nm}$ & & & & \\
\hline 0.1 & 0.072 & 0.20 & 0.064 & 0.24 & 0.059 & 0.18 \\
\hline 0.2 & 0.124 & 0.19 & 0.118 & 0.18 & 0.110 & 0.18 \\
\hline 0.3 & 0.175 & 0.24 & 0.160 & 0.20 & 0.150 & 0.19 \\
\hline 0.4 & 0.215 & 0.28 & 0.200 & 0.24 & 0.180 & 0.19 \\
\hline 0.5 & 0.235 & 0.27 & 0.215 & 0.22 & 0.190 & 0.19 \\
\hline 0.6 & 0.280 & 0.35 & 0.240 & 0.25 & 0.220 & 0.20 \\
\hline 0.7 & 0.290 & 0.33 & 0.250 & 0.24 & 0.225 & 0.20 \\
\hline 0.8 & 0.310 & 0.35 & 0.270 & 0.25 & 0.230 & 0.20 \\
\hline 0.9 & 0.315 & 0.33 & 0.285 & 0.26 & 0.237 & 0.19 \\
\hline 1.0 & 0.320 & 0.34 & 0.300 & 0.28 & 0.250 & 0.20 \\
\hline $\bar{R}_{\mathrm{c}} / \mathrm{nm}$ & \multicolumn{2}{|c|}{0.79} & \multicolumn{2}{|c|}{0.74} & \multicolumn{2}{|c|}{0.70} \\
\hline
\end{tabular}

$\left(c_{\mathrm{p}}=0.002 \mathrm{~mol} \mathrm{dm}^{-3} ; T=25^{\circ} \mathrm{C} ; I=0.02 \mathrm{~mol} \mathrm{dm}^{-3}\right.$. $)$ 
Table VI. Stokes's radii of some solvated metal ions $(\mathrm{nm})$ in various solvents

\begin{tabular}{|c|c|c|c|c|c|c|c|c|}
\hline & Water & Acetone & DMSO & \multicolumn{2}{|c|}{ Methanol } & Ethanol & $n$-Propanol & $r^{\mathrm{a}}$ \\
\hline $\mathrm{Li}^{+}$ & 0.24 & 0.37 & 0.32 & 0.38 & $0.48^{\mathrm{b}}$ & & & 0.068 \\
\hline $\mathrm{Na}^{+}$ & 0.18 & 0.35 & 0.30 & 0.33 & 0.44 & 0.38 & 0.40 & 0.097 \\
\hline $\mathrm{Cs}^{+}$ & & & 0.25 & 0.24 & 0.39 & 0.29 & 0.31 & 0.167 \\
\hline $\mathrm{Mg}^{2+}$ & & 0.77 & & 0.52 & 0.56 & & & 0.066 \\
\hline $\mathrm{Ca}^{2+}$ & & 0.65 & & 0.50 & 0.55 & & & 0.099 \\
\hline
\end{tabular}

${ }^{\mathrm{a}}$ Crystallographic radii from ref $35 .{ }^{\mathrm{b}}$ Corrected radii by Nightingale. Other values are from ref. 36.

prove this we compare them with the crystallographic and hydrated radii of the alkali and earth alkali counterions. They are listed in Table VI.

In order to bring a hydrated counterion into the volume $V_{\mathrm{c}}$, the distance $\left(R_{\mathrm{c}}-a\right)$ should be as large or larger than the diameter of the hydrated counterion. Unfortunately, this is not the case. The values of $\left(R_{\mathrm{c}}-a\right)$ are significantly smaller than the radii of the hydrated counterions. Thus, we could conclude that the Poisson-Boltzmann approach is not valid here. On the other hand, the crystallographic radii of the counterions are smaller than $\left(R_{\mathrm{c}}-a\right)$. That is, the $\left(R_{\mathrm{c}}-a\right)$ data become physically reasonable if we assume that the small ions release partly their hydration layers when they are bound to DS. If this assumption is correct, the attractive Coulomb-forces acting between the polyion charge and a bound counterion would be so strong that the counterion is no longer mobile. This would mean that the bound counterions are rather bound by site binding than by condensation. Since the average value of $\left(R_{\mathrm{c}}-a\right)$ becomes smaller with increasing methanol content, site binding is the more probable type of counterion binding the more organic solvent is added. Interestingly, the opposite effect is found in mixtures of water and formamide, where $\left(R_{\mathrm{c}}-a\right)$ increases with increasing formamide fraction. Thus, we come to the conclusion that in mixed solvents where the dielectric constant, $\varepsilon_{\mathrm{r}}$, increases with increasing organic solvent content, delocalized binding is the favorized type of binding, while in solvent mixtures where $\varepsilon_{\mathrm{r}}$ decreases, site binding is favorized. Following this interpretation we obtain new aspects concerning the competition between univalent and divalent counterions.

Table VII shows $\theta_{2, \exp ^{-}}$and $\left(R_{\mathrm{c}}-a\right)$-data, determined for the system $\mathrm{MgCl}_{2} / \mathrm{MCl} / \mathrm{MDS}$. The solvent is a mixture of $20 \% n$-propanol and $80 \%$ water, $c_{\mathrm{p}}$ is 0.002 mol dm ${ }^{-3}, I$ is $0.02 \mathrm{~mol} \mathrm{dm}^{-3}$, and $\mathrm{M}$ being $\mathrm{K}, \mathrm{Na}$, or $\mathrm{Li}$, respectively. Additionally, we have calculated the concentration, $c_{\mathrm{Mg}, \mathrm{b}}$, of the $\mathrm{Mg}^{2+}$ ions bound within the binding volume $V_{\mathrm{c}}$, i.e., $c_{\mathrm{Mg}, \mathrm{b}}=\theta_{2 \exp } /\left[\pi\left(R_{\mathrm{c}}-a\right)^{2} b\right]$. Values of $c_{\mathrm{Mg}, \mathrm{b}}$ are also given in Table VII.

Two effects are observed. Firstly, $c_{\mathrm{Mg}, \mathrm{b}}$ depends on the total divalent concentration, $c_{2}$. At $c_{2}=0, c_{\mathrm{Mg}, \mathrm{b}}$ is zero. With increasing $c_{2}$ we note an increase of $c_{\mathrm{Mg}, \mathrm{b}}$ up to a maximum, and finally $c_{\mathrm{Mg}, \mathrm{b}}$ decreases. This is contrary to the predictions of condensation theory, where $c_{\mathbf{M g}, \mathbf{b}}$ is constant, depending only on $\xi$. Secondly, at a given ratio $c_{2} / c_{\mathrm{p}}$, the distance $\left(R_{\mathrm{c}}-a\right)$ is smallest for the ion mixture $\mathrm{Mg}^{2+} / \mathrm{K}^{+}$and largest for the mixture $\mathrm{Mg}^{2+} / \mathrm{Li}^{+}$. The crystallographic radius of a $\mathrm{Mg}^{2+}$ ion is $0.066 \mathrm{~nm}$ and the hydrated radius of $\mathrm{Mg}^{2+}$ in pure $n$-propanol is of the order of $0.6 \mathrm{~nm}$. This may be interpreted that in a solution where $\mathrm{Li}^{+}$ions are in excess over $\mathrm{Mg}^{2+}$,
Table VII. Deduced $\left(R_{\mathrm{c}}-a\right)$ values for the system $\mathrm{MgCl}_{2} / \mathrm{MDS} / \mathrm{MCl}$ from measurements in a water/n-propanol $(20 / 80)$ mixture

$\left(c_{\mathrm{p}}=0.002 \mathrm{~mol} \mathrm{dm}^{-3} ; T=25^{\circ} \mathrm{C} ; I=0.02 \mathrm{~mol} \mathrm{dm}^{-3}\right.$.)

\begin{tabular}{|c|c|c|c|c|c|c|}
\hline \multirow{4}{*}{$c_{2} / c_{\mathrm{p}}$} & \multicolumn{6}{|c|}{ Counterion mixture } \\
\hline & \multicolumn{2}{|c|}{$\mathrm{Mg}^{2+} / \mathrm{K}^{+}$} & \multicolumn{2}{|c|}{$\mathrm{Mg}^{2+} / \mathrm{Na}^{+}$} & \multicolumn{2}{|c|}{$\mathrm{Mg}^{2+} / \mathrm{Li}^{+}$} \\
\hline & \multirow{2}{*}{$c_{\mathrm{Mg}, \mathrm{b}} \times 10^{3}$} & \multirow{2}{*}{$\frac{R_{\mathrm{c}}-a}{\mathrm{~nm}}$} & \multirow{2}{*}{$c_{\mathrm{Mg}, \mathrm{b}} \times 10^{3}$} & \multirow{2}{*}{$\frac{R_{\mathrm{c}}-a}{\mathrm{~nm}}$} & \multirow{2}{*}{$c_{\mathrm{Mg}, \mathrm{b}} \times 10^{3}$} & \multirow{2}{*}{$\frac{R_{\mathrm{c}}-a}{\mathrm{~nm}}$} \\
\hline & & & & & & \\
\hline 0.1 & 0.042 & 0.069 & 0.086 & 0.138 & 0.130 & 0.30 \\
\hline 0.2 & 0.112 & 0.068 & 0.170 & 0.129 & 0.242 & 0.30 \\
\hline 0.3 & 0.156 & 0.060 & 0.236 & 0.105 & 0.326 & 0.31 \\
\hline 0.4 & 0.208 & 0.077 & 0.290 & 0.229 & 0.378 & 0.33 \\
\hline 0.5 & 0.250 & 0.150 & 0.346 & 0.219 & 0.432 & 0.40 \\
\hline 0.6 & 0.274 & 0.133 & 0.374 & 0.309 & 0.486 & 0.43 \\
\hline 0.8 & 0.334 & 0.164 & 0.440 & 0.322 & 0.554 & 0.63 \\
\hline 1.0 & 0.380 & 0.168 & 0.470 & 0.322 & 0.572 & 0.68 \\
\hline 1.2 & 0.408 & 0.136 & 0.494 & 0.347 & 0.592 & 0.68 \\
\hline
\end{tabular}

magnesium ions are bound preferably by condensation, i.e., with retention of their hydration shells, while if $\mathrm{K}^{+}$ ions are in excess over $\mathrm{Mg}^{2+}$, the hydration shell is completely released and $\mathrm{Mg}^{2}+$ ions are bound by site binding. The reason may be a competition between the univalent and the divalent counterions for the free binding places. $\mathrm{A}^{+}{ }^{+}$ion is weaker bound by DS than $\mathrm{Na}^{+}$or $\mathrm{K}^{+}$ions. Two bound $\mathrm{Li}^{+}$ions can be replaced by one $\mathrm{Mg}^{2+}$ ion without changing the hydration layers of both the $\mathrm{Li}^{+}$and the $\mathrm{Mg}^{2+}$ ions. On the other hand, a $\mathrm{K}^{+}$ion is rather strongly bound, probably by site binding in $20 \% n$-propanol. The latter would mean that two bound $\mathrm{K}^{+}$ions can only be replaced by one $\mathrm{Mg}^{2+}$ ion if the hydration layer of the $\mathrm{Mg}^{2+}$ ion is transferred to the $\mathrm{K}^{+}$ions. Since such a transfer is more difficult than a simple replacement of the ions, $\theta_{2 \exp }\left(\mathrm{Li}^{+}\right)$is larger than $\theta_{2 \exp }\left(\mathrm{K}^{+}\right)$, especially when $c_{2} / c_{\mathrm{p}}$ is small. These ideas are pure speculations, but it seems that the Poisson-Boltzmann approach is more realistic than condensation theory. The latter assumes the small ions to be point charges while the former takes into account the radius of the ions.

Finally, we present a comparison for the degree of counterion binding obtained by the Poisson-Boltzmann approach and condensation theory. An appropriate example is the system $\mathrm{MgCl}_{2} / \mathrm{LiCl} / \mathrm{LiDS}$ dissolved in a mixture of $20 \% n$-propanol and $80 \%$ water; $c_{\mathrm{p}}=2 \times 10^{-3}$ mol dm ${ }^{-3}, I=0.02 \mathrm{~mol} \mathrm{dm}^{-3}$. Table VIII contains values of $\theta_{\mathrm{Cl}}, \theta_{\mathrm{Li}}$, and $\theta_{\mathrm{Mg}}$. The values of the left column are calculated by eq 25 of the Poisson-Boltzmann approach. The average diameter of a hydrated alkali ion in $n$ propanol is $0.6 \mathrm{~nm}$; the radius of the polyion skeleton is 
W. BARÉ, and E. NORDMEIER

Table VIII. Calculated $\theta_{i}$ values for the system $\mathrm{MgCl}_{2} / \mathrm{NaDS} / \mathrm{NaCl}$ in water $/ n$-propanol (20/80) mixture $\left(c_{\mathrm{p}}=0.002 \mathrm{~mol} \mathrm{dm}^{-3} ; T=25^{\circ} \mathrm{C} ; I=0.02 \mathrm{moldm}^{-3}\right.$.)

\begin{tabular}{|c|c|c|c|c|c|c|c|}
\hline \multirow{2}{*}{$c_{2} / c_{\mathrm{p}}$} & \multicolumn{4}{|c|}{ Poisson-Boltzmann } & \multicolumn{3}{|c|}{ Manning } \\
\hline & $\theta_{\mathrm{Cl}}$ & $\theta_{\mathrm{Na}}$ & $\theta_{\mathrm{Mg}}$ & $2 \theta_{\mathrm{Mg}}+\theta_{\mathrm{Na}}-\theta_{\mathrm{Cl}}$ & $\theta_{\mathrm{Na}}$ & $\theta_{\mathrm{Mg}}$ & $2 \theta_{\mathrm{Mg}}+\theta_{\mathrm{Na}}$ \\
\hline 0.1 & 0.002 & 0.843 & 0.085 & 1.011 & 0.580 & 0.074 & 0.728 \\
\hline 0.2 & 0.003 & 0.576 & 0.143 & 0.859 & 0.479 & 0.131 & 0.741 \\
\hline 0.3 & 0.003 & 0.444 & 0.184 & 0.809 & 0.406 & 0.174 & 0.753 \\
\hline 0.4 & 0.003 & 0.351 & 0.213 & 0.774 & 0.354 & 0.204 & 0.762 \\
\hline 0.6 & 0.003 & 0.253 & 0.254 & 0.758 & 0.287 & 0.245 & 0.777 \\
\hline 0.8 & 0.003 & 0.192 & 0.288 & 0.765 & 0.247 & 0.270 & 0.788 \\
\hline 1.0 & 0.003 & 0.145 & 0.310 & 0.760 & 0.220 & 0.288 & 0.796 \\
\hline 1.2 & 0.003 & 0.110 & 0.320 & 0.747 & 0.200 & 0.301 & 0.802 \\
\hline
\end{tabular}

$a=0.5 \mathrm{~nm}$. Thus, $R_{\mathrm{c}}$ is $1.1 \mathrm{~nm}$ and $\left(R_{\mathrm{c}}-a\right) / a=1.2$. The values $\theta_{\mathrm{Li}}$ and $\theta_{\mathrm{Mg}}$ of the right column are calculated by condensation theory, where $\theta_{\mathrm{Cl}}$ is zero per definition. Two effects can be observed. Firstly, the $\theta_{\mathrm{Cl}}$ values, determined by the Poisson-Boltzmann approach, are very small. They are of the order of zero, indicating that the number of coions trapped within the volume $V_{\mathrm{c}}$ is negligible small. Secondly, $\theta_{\mathbf{L i}}$ decreases with increasing $c_{2} / c_{\mathrm{p}}$ while $\theta_{\mathrm{Mg}}$ increases. Except at very low $c_{2} / c_{\mathrm{p}}$, the values of $\theta_{\mathrm{Li}}$ and $\theta_{\mathrm{Mg}}$ obtained by both theories are of the same order of magnitude. This leads to the conclusion that condensation theory and the Poisson-Boltzmann approach are consistent, a result which was also found by Zimm and Le Bret. ${ }^{27}$

\section{Selective Adsorption}

It is well known that in a mixed solvent the solvent composition at the polymer surface differs from that of the bulk solvent. In most cases the best solvent being preferably adsorbed by the polymer so that at the polymer surface the fraction of this solvent is larger than in the bulk. Such a selective adsorption of one of the solvent components changes the dielectric constant of the polymer domain. Since the dielectric constant determines the value of the charge density parameter, $\xi$, selective adsorption should have a significant effect on the degree of counterion binding of polyions. Experimentally, selective adsorption can be examined by static light scattering, if the difference, $\left|n_{\mathrm{A}}-n_{\mathrm{B}}\right|$, between the refractive indices of the solvent components, $\mathrm{A}$ and $\mathrm{B}$, is larger than 0.03 . Otherwise, the solvent mixture is isorefractive, i.e., it behaves as if it were a single solvent. For our experiments we have chosen the mixtures water/ formamide and water/dimethyl sulfoxide (DMSO). The refractive index of pure water at $25^{\circ} \mathrm{C}$ and $\lambda_{0}=$ $546 \mathrm{~nm}$ is 1.334 , the refractive index of formamide is 1.448 , and that of DMSO is 1.477 . That is, the condition $\left|n_{\mathrm{A}}-n_{\mathrm{B}}\right|>0.03$ is fulfilled in both cases. Figure 10 shows a plot of the selective adsorption parameter, $\alpha_{\mathrm{a}}$, versus the molar fraction, $X_{\mathrm{o}}$, of the organic component in the bulk solvent. $\alpha_{\mathrm{a}}$ being determined by eq 20 . At low and intermediate values of $X_{\mathrm{o}}, \alpha_{\mathrm{a}}$ is negative for water/ formamide as well as for water/DMSO. This implies that formamide and DMSO, respectively, are adsorbed preferably over water by DS as long as $X_{\mathrm{o}}$ is sufficiently small. For larger values of $X_{\mathrm{o}}, \alpha_{\mathrm{a}}$ becomes positive, indicating that water is the preferred solvent.

From $\alpha_{\mathrm{a}}$ the number $X_{\mathrm{A}}$ of the solvent molecules of

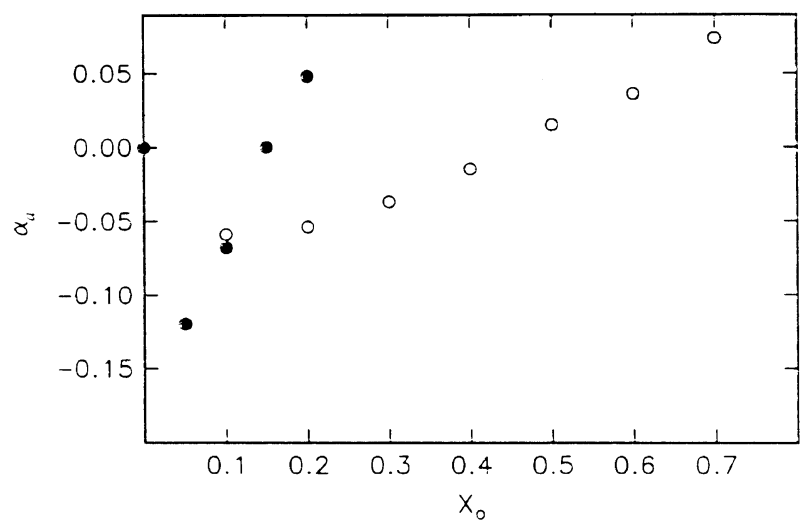

Figure 10. Plots of $\alpha_{\mathrm{a}}$ vs. $X_{\mathrm{o}}$ for water/DMSO (O) and water/ formamide ( $\bigcirc)$ mixtures. $\alpha_{\mathrm{a}}$ in $\mathrm{cm}^{3} \mathrm{~mol} \mathrm{~g}^{-1}$.

Table IX. Values of $X_{\mathrm{A}}$ for $\mathrm{H}_{2} \mathrm{O} /$ DMSO and $\mathrm{H}_{2} \mathrm{O}$ /formamide

( $X_{\mathrm{o}}$ and $X_{\mathrm{o}, \mathrm{s}}$ are the molar fractions of the organic solvent) in the bulk and at the polyion surface.

\begin{tabular}{ccccccc}
\hline \multicolumn{3}{c}{$\mathrm{H}_{2} \mathrm{O} / \mathrm{DMSO}$} & & & \multicolumn{3}{c}{$\mathrm{H}_{2} \mathrm{O} /$ Formamide } \\
\cline { 1 - 3 } \cline { 5 - 7 }$X_{\mathrm{o}}$ & $X_{\mathrm{o}, \mathrm{s}}$ & $X_{\mathrm{A}}$ & & $X_{\mathrm{o}}$ & $X_{\mathrm{o}, \mathrm{s}}$ & $X_{\mathrm{A}}$ \\
\hline 0.00 & 0.00 & 0.00 & & 0.00 & 0.00 & 0.00 \\
0.05 & 0.09 & 0.64 & & 0.10 & 0.16 & 0.48 \\
0.10 & 0.15 & 0.35 & & 0.20 & 0.33 & 0.44 \\
0.15 & 0.15 & 0.00 & & 0.30 & 0.45 & 0.30 \\
0.20 & 0.13 & -0.25 & & 0.40 & 0.48 & 0.12 \\
0.25 & 0.10 & -0.46 & & 0.50 & 0.40 & -0.13 \\
& & & & 0.60 & 0.34 & -0.29 \\
& & & & 0.70 & 0.17 & -0.60 \\
\hline
\end{tabular}

type A adsorbed preferably per DS monomer unit with respect to the bulk solvent can be calculated. If $\alpha_{\mathrm{a}}<0$ it holds

$$
X_{\mathrm{A}}=\left|\alpha_{\mathrm{a}}\right| \frac{M_{\mathrm{o}}}{\overline{V_{\mathrm{A}}}}
$$

where $M_{\mathrm{o}}$ is the molar mass of a DS monomer unit and $V_{\mathrm{A}}$ the partial molar volume of solvent $\mathrm{A}$. In most cases, the molar volume can be used instead of $\overline{V_{\mathrm{A}}} \cdot X_{\mathrm{A}}$ takes on values between 0 and 1 . If $w_{\mathrm{A}}=0$ or $w_{\mathrm{A}}=1, X_{\mathrm{A}}$ is zero because in these cases we have single solvents and selective adsorption cannot occur. Values of $X_{\mathrm{A}}$ are given in Table IX. We observe that $X_{\mathrm{A}}$ does not exceed 0.64 which corresponds to the preferential adsorption of nearly two molecules of solvent A by three DS monomer units. It seems that the affinity for selective adsorption is larger for water/formamide than for water/DMSO. 
The reason may be that the amide group of formamide is positively charged. That means, formamide can bind electrostatically to a DS sulfate group, while DMSO cannot. It is also well known that there are specific interactions between DMSO and water molecules. The free excess enthalpie, $\Delta G_{\mathrm{ex}}$, the excess enthalpie, $\Delta H_{\mathrm{ex}}$, and the excess entropie, $\Delta S_{\text {ex }}$, are negative. ${ }^{38}$ That is, the $\mathrm{H}_{2} \mathrm{O}$ molecules are stronger oriented in $\mathrm{DMSO} / \mathrm{H}_{2} \mathrm{O}$ than in the structure of pure water. At $T=25^{\circ} \mathrm{C}$ the minimum of $\Delta G_{\mathrm{ex}}$ is at the mol fraction $X_{\mathrm{DMso}}=0.32$. This is remarkable because DS precipitates near this mark. It is postulated $^{39}$ that $\mathrm{H}_{2} \mathrm{O}$ and DMSO build stabil DMSO$\left(\mathrm{H}_{2} \mathrm{O}\right)_{2}$ complexes, so that at the precipitation point neither free DMSO nor $\mathrm{H}_{2} \mathrm{O}$-molecules are present.

The next step is to calculate the dielectric constant, $\varepsilon_{\mathrm{r}}$, at the polyion surface. First of all we have to determine the molar fraction $X_{\mathrm{o}, \mathrm{s}}$ of the organic solvent at the surface. If $\alpha_{\mathrm{a}}<0$, it holds

$$
X_{\mathrm{o}, \mathrm{s}}=\frac{1+X_{\mathrm{A}}}{X_{\mathrm{o}}^{-1}+X_{\mathrm{A}}\left(1-v_{\mathrm{A}} / v_{\mathrm{B}}\right)}
$$

where $X_{\mathrm{o}}$ is the molar fraction of the organic solvent component in the bulk solvent, $v_{\mathrm{A}}$ and $v_{\mathrm{B}}$ are the molar volumes of solvent $\mathrm{A}$ and $\mathrm{B}$, and $X_{\mathrm{A}}$ is given by eq 26 . For this purpose we need a relation between $\varepsilon_{\mathrm{r}}$ and $X_{\mathrm{o}}$. Nonlinear regression of literature data $^{31}$ at $T=25^{\circ} \mathrm{C}$ yields

$$
\begin{gathered}
\varepsilon_{\text {DMSO }}=80.3-13.89 X_{\mathrm{o}}-42.93 X_{\mathrm{o}}^{2}+20.56 X_{\mathrm{o}}^{3}+2.49 X_{\mathrm{o}}^{4} \\
\varepsilon_{\text {Formamide }}=78.7+169.65 X_{\mathrm{o}}-551.93 X_{\mathrm{o}}^{2}+1101.3 X_{\mathrm{o}}^{3} \\
-1087.08 X_{\mathrm{o}}^{4}+399.09 X_{\mathrm{o}}^{5}
\end{gathered}
$$

Inserting $X_{\mathrm{o}, \mathrm{s}}$ into eq 28 or 29 , respectively, we get the dielectric constant $\varepsilon_{\mathrm{s}}$, of the solvent at the polymer surface. Figure 11 shows plots of $\varepsilon_{\mathrm{r}}$ versus $X_{\mathrm{o}}$. The solid lines present the dielectric constant, $\varepsilon_{\mathrm{b}}$, of the bulk while the dashed lines are the corresponding $\varepsilon_{\mathrm{s}}$ values at the polyion surface. For water/formamide at low and intermediate $X_{\mathrm{o}}, \varepsilon_{\mathrm{s}}$ is larger than the dielectric constant, $\varepsilon_{\mathrm{b}}$, of the bulk while for large $X_{\mathrm{o}}, \varepsilon_{\mathrm{b}}$ becomes larger than $\varepsilon_{\mathrm{s}}$. The opposite behavior is observed for the system water/ DMSO. If $\theta_{\mathrm{b}}$ is the degree of counterion binding calculated for $\varepsilon_{\mathrm{b}}$ and $\theta_{\mathrm{s}}$ the corresponding value for $\varepsilon_{\mathrm{s}}$, the theoretical expectation is that $\theta_{\mathrm{s}}<\theta_{\mathrm{b}}$ for water/ formamide and $\theta_{\mathrm{s}}>\theta_{\mathrm{b}}$ for water/DMSO as long as $X_{\mathrm{o}}$ is low. Unfortunately, the experiments show the inverse effect. For water/formamide, $\theta_{\exp }$, which should be compared with $\theta_{\mathrm{s}}$, is larger than $\theta_{\mathrm{b}}$, while for water/ DMSO $\theta_{\exp }$ is smaller than $\theta_{\mathrm{b}}$. We cannot provide an explanation now, but it becomes more and more unprobable that there is a universal correlation between $\theta$ and $\varepsilon_{\mathrm{r}}$ which is common to all solvents. According to this aspect condensation theory is incorrect. The solvent cannot be considered as a continuum of uniform dielectricum. An improved theory has to take into account the individual chemical structure of the solvent, small ion-solvent interactions, and polyion-solvent interactions (selective adsorption). In addition, it is questionable whether in mixed solvents the Debye-Hückel theory is applicable. Neither $\varepsilon_{\mathrm{r}}$ is constant nor solvated small ions are point charges.
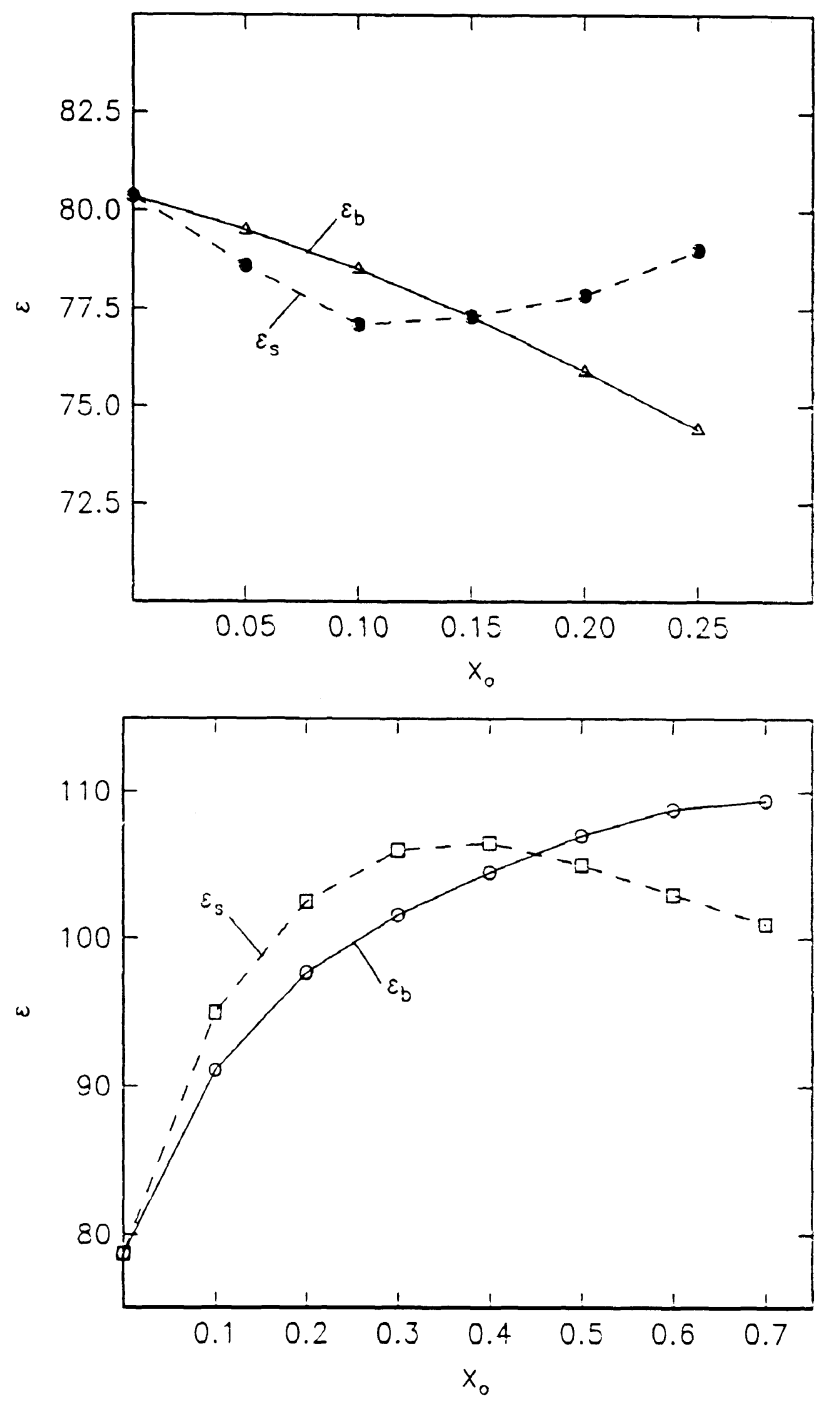

Figure 11. Plots of $\varepsilon$ vs. $X_{\mathrm{o}}$ for water/DMSO (above) and water/formamide (below).

\section{CONCLUSIONS}

We have studied the behavior of dextran sulfate and dextran phosphate in various mixed solvents consisting of water and an organic solvent, where the latter is a precipitant for DS as well as for DP. It could be shown that in mixed solvents completely new phenomena occur that do not exist in pure water. Mainly the following phenomena are observed:

1. While in pure water the predictions of counterion condensation theory are valid, they are incorrect in mixed solvents. There is no universal correlation between the dielectric constant, $\varepsilon_{\mathrm{r}}$, of the solvent and the degree of counterion binding, $\theta$.

2. In mixed solvents selective adsorption occurs. One solvent component is adsorbed preferably by the polyion so that the dielectric constant, $\varepsilon_{\mathrm{s}}$, at the polyion surface differs significantly from that of the bulk solvent.

3. For pure water and DS we find the ion sequence $\mathrm{Cs}^{+}>\mathrm{K}^{+}>\mathrm{Na}^{+}>\mathrm{Li}^{+}$, while for DP it holds $\mathrm{Cs}^{+}<$ $\mathrm{K}^{+}<\mathrm{Na}^{+}<\mathrm{Li}^{+}$. In a mixed solvent the orders change. They depend on the solvent mixture used.

4. The accuracy of the results of measurements depends sensibly on the method used. For mixed solvents 
the accuracy is highest for dye spectroscopy and light scattering but rather low for ionic sensitive electrodes (ISE) and dialysis. The reason is that the membranes used for ISE and dialysis are affected by organic solvent component in many cases so that they become useless.

5. In mixed solvents the dependence of the degree of counterion binding on the concentration of the added salt can be more realistic described by the PoissonBoltzmann approach than by condensation theory. In the Poisson-Boltzmann approach the radius of hydration of the small ions can be taken into account, while according to the condensation theory counterions are handled as point charges. The results derived from the Poisson-Boltzmann approach are, on the other hand, surprising in some aspects. It is found that in a mixed solvent the type of divalent counterion binding, such as $\mathrm{Mg}^{2+}$ binding, depends on the kind of the univalent counterion added in excess. For instance, in the presence of $\mathrm{Li}^{+}, \mathrm{Mg}^{2+}$ binds to DS preferably by delocalized binding while in the presence of $\mathrm{Cs}^{+}$is binds preferably by site binding. A proof of this assumption is difficult, but possible. NMR and neutron scattering experiments may be helpfull. Such studies are planned for the future.

6. The paper contains several aspects, i.e., specific polyion/counterion interaction, inhomogeneity of dielectric constant, usefulness of the Poisson-Boltzmann or Manning treatment, etc., where the relations between the different aspects are unclear. To clarify these aspects theory must be modified. Manning assumes that the solvent is a continuum of constant dielectric permittivity $\varepsilon_{\mathrm{r}}$. For a simple solvent, such as pure water, this may be a good approximation, but for a binary solvent it is not. Firstly, the structure of the solvent in the solvation shell of a small ion is different from that in bulk. Secondly, as a result of selective solvation the solvent composition in the solvation shell of a bound counterion is different from that in the shell of a free counterion. Thus theory has taken into account a medium effect, i.e., a transfer free enthalpie for the transfer of a free hydrated counterion into the condensation volume $V_{c}$. An interesting starting point may be the theory of Waghorne ${ }^{40}$ treating simple electrolytes in mixed solvents. Simultaneously, the inhomogeneity of $\varepsilon_{\mathrm{r}}$, which is also a problem for aqueous systems, should be solved. This is a diffusion problem, such as the distribution of ions at the surface of a charged membrane, but it is complicated by the fact that the ions are hydrated. That is, the Poisson-Boltzmann equation must be coupled with a counterion/coion diffusion equation and both equations must be solved simultaneously for $\varepsilon(r)$ and $\Psi(r)$, where $\varepsilon(r)$ and $\Psi(r)$ are the dielectric constant and the electrostatic potential at the distance $r$ from the polyion axis. Finally, it seems, that counterion/counterion interactions within $V_{\mathrm{c}}$ may be important. The reason is, that different counterions compete both for the free polyion binding places as well as for the solvent molecules preferably adsorbed by the ions. However, at the moment we have no idea how this competition can be described theoretically.

7. For PSS we have found that there is a correlation between $\theta$ and $\varepsilon_{\mathrm{r}}{ }^{2}$ DS and DP are branched polyelectrolytes and there is no correlation between $\theta$ and $\varepsilon_{\mathrm{r}}$.
Thus we could conclude that branching disturbs the correlation between $\theta$ and $\varepsilon_{\mathrm{r}}$. However, we do not believe so. DS and DP are ionic polysaccharides while PSS is not. Since pullulan is the linear analogon of dextran it may be more reasonable to compare the behavior of pullulan sulfate and pullulan phosphate with that of DS and DP, respectively. Such studies are in work now.

Acknowledgements. We thank Prof. Dr. M. D. Lechner for providing laboratory facilities and the Friedrich-Naumann-Stiftung for financial support.

\section{REFERENCES}

1. E. Nordmeier, Polym. J., 25, 1 (1993).

2. E. Nordmeier, Macromol. Chem. Phys., 196, 1321 (1995).

3. E. Nordmeier, Polym. J., 26, 539 (1994).

4. E. Nordmeier and M. D. Lechner, Macromolecules, 24, 2529 (1991).

5. U. Sedlack and E. Nordmeier, Eur. Polym. J., in press (1996).

6. R. A. Mock and C. A. Marshall, J. Polym. Sci., 13, 263 (1953)

7. G. S. Manning, J. Chem. Phys., 51, 924 (1969).

8. Y. M. Joshi and J. C. T. Kwak, Biophys. Chem., 8, 191 (1978).

9. M. Kowblansky and P. Zema, Macromolecules, 14, 166 (1981).

10. K. Iwasa and J. C. T. Kwak, J. Phys. Chem., 81, 408 (1977).

11. K. Iwasa, D. A. McQuarrie, and J. C. T. Kwak, J. Phys. Chem., 82, 1979 (1978).

12. G. S. Manning, Quart. Rev. Biophys., 11, 179 (1978).

13. R. L. Whistler and G. A. Towle, Arch. Biochem. Biophys., 135, 396 (1969).

14. Y. M. Joshi and J. C. T. Kwak, Biophys. Chem., 13, 56 (1981).

15. R. A. Robinson and R. H. Stokes, "Electrolytes Solutions," Butterworth's, London, 1970.

16. T. Ooi, J. Polym. Sci., 28, 459 (1958).

17. E. F. Casassa and H. Eisenberg, "Advances in Protein Chemistry," Academic Press, New York, 1964.

18. G. M. Barrow, "Physikalische Chemie," Teil 3, Bohmann-Vieweg, Wien and Braunschweig, 1984.

19. I. Satake, M. Fukuda, T. Ohta, K. Nakamura, N. Fujita, A. Yamauchi, and H. Kimizuka, J. Polym. Sci., Phys. Ed., 10, 2343 (1972).

20. K. Gekko and H. Noguchi, "Reports on Progress in Polymer Physics in Japan," Vol. 21, 1978, p 683.

21. T. J. Padlos and P. Ander, Macromolecules, 2, 432 (1969).

22. F. Tanaka and H. Ushiki, Macromolecules, 21, 1041 (1988).

23. D. Volmer, Master's thesis, Universität Osnabrück, FB Phys. Chemie (1991).

24. J. Mattai and J. C. T. Kwak, J. Phys. Chem., 86, 1026 (1982).

25. Y. M. Joshi and J. C. T. Kwak, Biophys. Chem., 13, 65 (1981).

26. G. Weisbuch and M. Guéron, J. Phys. Chem., 85, 517 (1981).

27. M. Le Bret and B. H. Zimm, Biopolymers, 23, 287 (1984).

28. D. Stigter, J. Phys. Chem., 82, 1603 (1978).

29. E. Kausen, "Numerische Mathematik mit Turbo-Pascal," Dr. Alfred Hüthig Verlag GmbH, Heidelberg, 1989, p 193.

30. A. Peterlin and Davorin Dolar, J. Chem. Phys., 50, 3011 (1969).

31. L. Börnstein, Numerical Data and $\cdots$. Springer Verlag, Berlin, 1991.

32. G. Åkerlöf, J. Am. Chem. Soc., 54, 4125 (1932).

33. G. Åkerlöf and O. A. Short, J. Am. Chem. Soc., 58, 1241 (1936).

34. Yu. M. Kessler, V. P. Emelin, Yu. S. Tolubeev, O. V. Truskow, and R. M. Lapshin, Zhurnal Strukturnoi Khimii, 13, 210 (1972).

35. A. F. Hollemann and N. Wiberg, "Lehrbuch der Anorganischen Chemie," Walter de Gruyter \& Co., Berlin, 1985.

36. J. Burgess, "Metal Ions in Solution," Ellis Horwood Limited, Chichester, Sussex, England, 1978, p 164.

37. K. Gekko and H. Noguchi, Macromolecules, 7, 224 (1974).

38. J. M. C. Cowie and P. M. Toporowski, Canad. J. Chem., 39, 2240 (1961).

39. J. J. Lindberg and J. Kenttämaa, Suomen Kemistilehti, B33, 104 (1960).

40. W. E. Waghorne, Chem. Soc. Rev., 22, 285 (1993). 